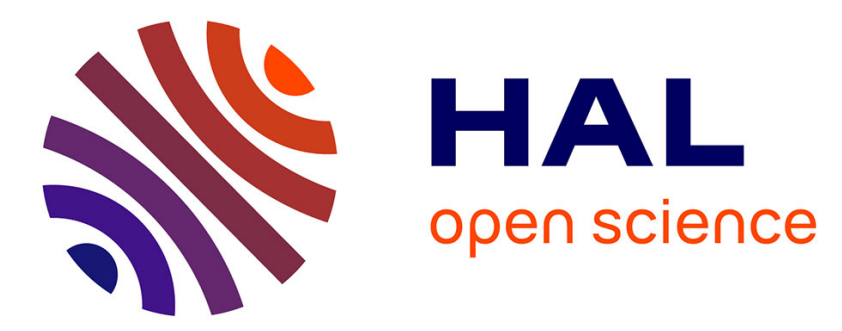

\title{
A systematic framework of vulnerability analysis of a natural gas pipeline network
}

Huai Su, Enrico Zio, Jinjun Zhang, Xueyi Li

\section{To cite this version:}

Huai Su, Enrico Zio, Jinjun Zhang, Xueyi Li. A systematic framework of vulnerability analysis of a natural gas pipeline network. Reliability Engineering and System Safety, 2018, 175, pp.79 - 91. 10.1016/j.ress.2018.03.006 . hal-01786581

HAL Id: hal-01786581

https://hal-centralesupelec.archives-ouvertes.fr/hal-01786581

Submitted on 27 Apr 2020

HAL is a multi-disciplinary open access archive for the deposit and dissemination of scientific research documents, whether they are published or not. The documents may come from teaching and research institutions in France or abroad, or from public or private research centers.
L'archive ouverte pluridisciplinaire HAL, est destinée au dépôt et à la diffusion de documents scientifiques de niveau recherche, publiés ou non, émanant des établissements d'enseignement et de recherche français ou étrangers, des laboratoires publics ou privés. 
A systematic framework of vulnerability analysis of a natural gas pipeline network

Huai Su, Enrico Zio, Jinjun Zhang, Xueyi Li

PII: S0951-8320(17)31165-1

DOI: 10.1016/j.ress.2018.03.006

Reference: RESS 6088

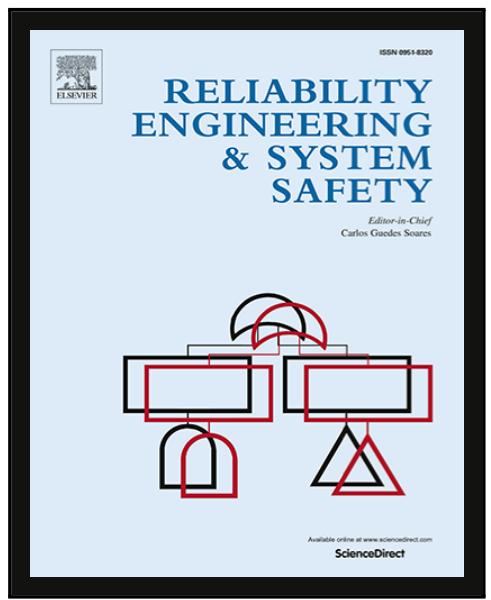

To appear in:

Reliability Engineering and System Safety

Received date:

27 September 2017

Revised date: $\quad 6$ January 2018

Accepted date:

3 March 2018

Please cite this article as: Huai Su, Enrico Zio, Jinjun Zhang, Xueyi Li, A systematic framework of vulnerability analysis of a natural gas pipeline network, Reliability Engineering and System Safety (2018), doi: 10.1016/j.ress.2018.03.006

This is a PDF file of an unedited manuscript that has been accepted for publication. As a service to our customers we are providing this early version of the manuscript. The manuscript will undergo copyediting, typesetting, and review of the resulting proof before it is published in its final form. Please note that during the production process errors may be discovered which could affect the content, and all legal disclaimers that apply to the journal pertain. 


\section{Highlights}

- A method is developed to analyze vulnerability of gas pipeline networks.

- Supply capacity, gas grid performance and demand change are considered.

- Indices are developed to measure gas grid vulnerability and pipeline criticality.

- Demand site robustness is analyzed by statistics and topology properties.

- The application of the method is studied in a complex natural gas pipeline network. 


\title{
A systematic framework of vulnerability analysis of a natural gas pipeline network
}

\author{
Huai $\mathrm{Su}^{\text {a }}$, Enrico Zio ${ }^{\mathrm{b}, \mathrm{c}}$ Jinjun Zhang ${ }^{\mathrm{a}^{*}}$, Xueyi $\mathrm{Li}^{\mathrm{a}}$ \\ ${ }^{a}$ National Engineering Laboratory for Pipeline Safety/ MOE Key Laboratory of \\ Petroleum Engineering /Beijing Key Laboratory of Urban Oil and Gas Distribution \\ Technology, China University of Petroleum-Beijing, 102249, Beijing, China \\ ${ }^{\mathrm{b}}$ Dipartimento di Energia, Politecnico di Milano, Via La Masa 34, 20156, Milano, \\ Italy \\ ${ }^{\mathrm{c}}$ Chair System Science and the Energy Challenge, Fondation Electricité de France \\ (EDF), CentraleSupélec, Université Paris Saclay, Grande Voie des Vignes, 92290 \\ Chatenay-Malabry, France
}

\begin{abstract}
\end{abstract}
A systematic framework is developed to assess the vulnerability of natural gas pipeline networks. To measure the impact of accidents on gas supply service, a consequence model is developed based on a flow algorithm embedded into an optimization scheme, with the consideration of physical constraints. The vulnerability analysis is performed from three viewpoints: global vulnerability analysis, demand robustness and critical pipeline analysis. The global vulnerability analysis is performed considering hazards and threats in gas sources, demand and transmission system. The analysis of demand robustness evaluates the capacities of demand sites to withstand

\footnotetext{
* Corresponding author. Address: College of Mechanical and Transportation Engineering, China University of Petroleum, Fuxue Road 18, Changping District 102249, Beijing, China. Tel.: +86-10-8973 4627; fax: +86-10-8973 4627. E-mail address: zhangjj@cup.edu.cn
} 
the strains imposed on the pipeline network system and further explains the differences in capacities, from a graph theory perspective. In the critical pipeline analysis, criticalities of pipelines are evaluated by considering direct attacks and using a physical flow-based method. The analyses are performed on a relatively complex gas pipeline network taken from literature.

Key words: complex natural gas pipeline network; vulnerability analysis; supply service; max-flow algorithm; Floyd algorithm; criticality analysis

\section{Introduction}

Reliable natural gas supply service from natural gas pipeline networks is important for society stability and economy development. Although many efforts have been done, potential vulnerabilities still exist because of system structure complexity, uncertain environment, resource limitation and demand fluctuation. When unexpected events occur, e.g., extreme weather events, terrorist attacks, third-party activities, political crisis, etc., severe consequences may follow [1][3].

On this background, efforts have been done to assess and improve the reliability and security of natural gas pipeline networks. Generally, the classical methods of reliability theory and risk management have been used. Reliability theory supports the analysis of the ability of systems to perform their functions under given operational and environmental conditions, for a defined period of time [4], [5]. Risk management considers both the probabilities of failures and the negative consequences [6]. However, challenges emerge in their application to large complex network systems [6]-[9]. On that account, one must go beyond the probabilistic estimation addressing the problem also from a vulnerability point of view [10], [11]. 
In recent years, the vulnerability analysis of large complex transmission networks has been given increasing attention in many application areas, e.g., power grids [12], [13], Internet [14], transportation systems [15], [16], etc. However, the importance of vulnerability in gas pipeline networks has not been given enough attention to.

Vulnerability is a term which is applied with several different definitions in the literature. In this research, vulnerability is defined as inherent system defects to withstand the strains, i.e. to absorb the effects of failures or to quickly restore the system to normal performance. Vulnerability analysis focuses on the inherent properties rather than environment and probabilities, as reliability and risk do. Applying vulnerability analysis to evaluate the supply serviee of gas pipeline network systems can help to improve the knowledge about their inabilities under different strains and to find the "bottlenecks" of a natural gas pipeline network system. The strains in a gas pipeline network represent disturbances or unexpected events (e.g., pipeline failure, demand fluctuation, gas source interruption or some other events), which can cause degenerations of system capacities to reliably serve customers.

In general, vulnerability analysis can be performed by empirical methods or simulation methods [17]. Empirical methods are performed based on historical data and information of accidents. The vulnerability analysis of complex network transmission systems, e.g., power grids, railway systems, water networks, are mostly carried out by simulation methods because of the system complexity. The key of simulation methods is to develop models which can be used to analyze the effects of failures at system level and find potential high-consequence events. A number of methods or theories are capable to model different systems from different perspectives. From topological/structural perspectives, graph theory and statistical physics allow describing the 
connectivity properties of complex systems, evaluating the effects on system functionality and locating the critical parts [18]-[23]. Logical methods, such as game theory and hierarchical logic trees, can capture the logic of dysfunction of a complex system [24]-[29]. Functional/phenomenological methods, e.g. system dynamic methods, control theory, agent-based modeling, etc. help capturing the dynamic properties of systems [30]-[35].

Evaluation of element criticality is an important part of vulnerability analysis. In a network transmission system, element criticality evaluation is usually carried out based on the system structure or the consequences of failures. From the perspective of system structure, several identification methods have been proposed based on different considerations, e.g. network efficiency [36], [37], flow-based performance [21], [38]-[41], cost of travel time [42], accessibility [43], [44], etc. In the consequence-based methods, criticality of element is evaluated according to the direct, and sometimes indirect, effect of the failure [45].

In natural gas pipeline networks, shortage at demand sites can result in severe consequences because every demand node can play an important role, such as gate stations of city distribution networks, power plants or factories [2], [46]. Considering that it is insufficient to focus on the global capacity of the gas pipeline network system, one should also pay enough attention to the effects of strains on each demand site. In related works, many efforts have been done on demand side management [47]-[50]. However, to provide a reliable service, it is not sufficient to just mannage the demands. One should also find out the effects of the strain imposed on the system [51].

Vulnerability analysis of supply service requires a model that is capable of capturing the behavior of the system, the supply capacity and the amount of gas requested at demand sites. 
Thermal-hydraulic analysis and system dynamic methods can perform detailed consequence analysis; however, they are not suitable to the vulnerability analysis because of the huge computational cost due to rather detailed numerical simulations. Hence, it is important to develop a computation-efficient model that can capture system behaviors and calculate supply capacity of gas pipeline networks.

In this paper, a method of vulnerability analysis of natural gas supply service pipeline networks is developed considering global vulnerability analysis, critical pipeline analysis and customers' robustness analysis. Global vulnerability and customers' robustness/are two matrices of vulnerability of gas pipeline networks from different perspectives: the former emphasizes the overall system ability to withstand strains and the latter focuses on the potential impacts of strains on individual customers. Global vulnerability, analysis aims at evaluating the ability of a gas pipeline network to withstand different "strains" and estimating the negative consequences (Section 3.1). Analysis of robustness of demand sites focuses on their different abilities to withstand strains imposed on the system and explains their differences from the perspective of system structure (Section 3.2). Critical pipeline analysis uses different methods (flow-based method and consequence estimation) to evaluate the criticalities of pipelines (Section 3.3). In Section 2, a system model is developed based on network flow theory, combined with an optimization part. The model can simulate the system behaviors and the adjustments of the transmission plan in different conditions, and estimate the supply capacities of both the global system and the demand sites, with the consideration of physical constraints.

\section{Natural gas pipeline network model for consequence calculation}




\subsection{Modeling of natural gas pipeline networks}

For the development of the consequence assessment model, only the components relating to gas supply capacity in the pipeline networks are considered, i.e. pipelines, compressor stations, gas sources and consumers. This is because the objective of the assessment is supply service. The development of the model of capacity/consequence analysis has followed the steps in Fig. 1.

The inputs of the model include:

A. Pipeline parameters: diameter, length, roughness etc.

B. Parameters of compressor stations;

C. Properties of natural gas;

D. Information of gas sources: locations, types, capacities;

E. Information of consumers: locations, demands;

F. Topology information of the pipeline network structure.

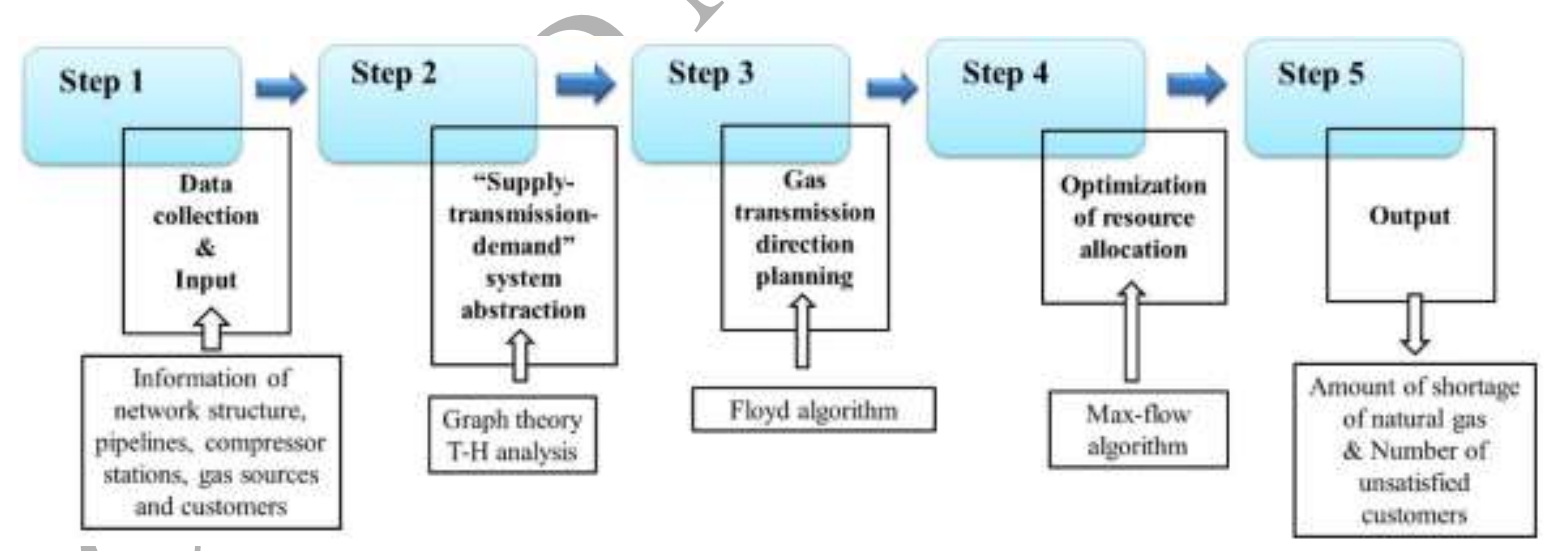

Fig. 1 Process of modeling for consequence analysis

\subsection{Natural gas supply-transmission-demand system abstraction}

On the basis of the inputs in Section 2.1, the pipeline network is abstracted in the form of a directed weighted network. The gas sources, consumers, pipeline junctions are represented as nodes and pipelines are represented as arcs. The weights on the arcs denote the transportation 
capacities of the pipelines. The transportation capacities are calculated by thermal-hydraulic analysis, based on the above inputs A, B and C. The T-H models of pipelines are developed by the steady mode and the overall network system is validated in TGNET - a professional software for gas pipeline modeling [52]. When the capacities of the pipelines change, the weights in the directed weighted network also change accordingly.

In general, if an unexpected negative event occurs, operators will take steps to withstand the strain and reduce the negative impacts. In general, the strategies include adjustment of gas sources, adjustment of directions of gas flows in the network and re-distribution of gas. In this model, all these strategies can be swiftly performed by changing the weights on the arcs. The optimization process will be introduced in the next Sections 2.3 and 2.4.

\subsection{Modeling of gas transmission optimization}

The optimization model represents the build-in property of natural gas pipeline networks to respond to unexpected interruptions and abnormal conditions. In this model, economic efficiency and supply distance are considered as the most relevant attributes to gas transmission planning. Firstly, a "standard cost" matrix $C$ is developed based on network topology and the network element cost is calculated by equation 1 . This so-called "standard cost", which is determined by the cost of transmission and pipeline length, represents a factor for the optimization of the transmission path, not a real cost:

$$
C_{i j}=\alpha L_{i j} \times \beta\left(Q_{i j} \times c\right)
$$

where $L_{i j}$ represents the length of the pipeline from node $i$ to node $j$ in the network $(\mathrm{km}) ; Q_{i j}$ represents the designed quantity of natural gas transported from $i$ to $j(\mathrm{MCM})$; $\mathrm{c}$ represents the cost of gas transportation $(\$ /(\mathrm{km} \cdot \mathrm{MCM})) ; \alpha$ and $\beta$, ranging from 0 to 1 , represent the importance 
weights of distance and cost of transmission, respectively; $C_{i j}$ represents the optimization factor combining cost and distance (\$). Although the unit of the so-called "standard cost" is $\$$, it is different from the actual cost. The "standard cost" matrix $C$ is re-calculated to optimize the transmission path in every scenario.

Then, "standard cost" vectors are calculated based on matrix $C$. Each of the vector contains the "standard cost" of the "shortest paths" between a gas source and all remaining non-source nodes, found by the Floyd algorithm [53]. In order to identify the sequence of the nodes that the gas flow from different sources should follow in its path, the "standard cost" yectors are sorted in ascending order. For a specific gas source, priority is given to the nodes with lower "standard cost", which means relatively higher efficiency and lower cost.

The algorithm will check whether the capacity of the source is exhausted: if there are still unsatisfied customers and residual capacity, the algorithm will search for the next unsatisfied demand node in the "standard cost" vectors. This process continues until all demands are satisfied or the residual capacity of the source is zero.

\subsection{Supply capacity calculation}

On the basis of the transmission directions determined in Section 2.3, we proceed to optimize the plan of natural gas distribution in the pipeline network (volume of gas supplied by different sources and gas flow in the pipelines). This problem is converted to a max-flow problem in graph theory and solved by Ford-Fulkerson algorithm.

Ford-Fulkerson algorithm is carried out by two steps [53]:

- Searching paths which connect the sources and the sinks with available capacities on the arcs. 
- Repeating the search process until no additional flow can be added to the path.

Also, two constraints are to be respected:

- The sum of the flow entering a node is equal to the sum of the flow exiting the node (except for the source and sink nodes).

- The flow in the arcs is within the allocated ranges of capacities.

Ford-Fulkerson algorithm is developed to solve the "single source and sink" problem. However, in general, gas pipeline networks usually have more than one source or sink. To convert this "multiple sources and sinks" problem to a "single source and sink" problem, we assume a "super source" and a "super sink" that connect with all the sources and sinks by edges with unlimited capacities.

Finally, the model will output the supply capacities at the demand sites in the pipeline network. By comparing with the demands requested, the gaps between demand and supply and the amount of unsatisfied customers are calculated as inputs of the vulnerability analysis. This optimization process will be repeated in every scenario to determine the plan of gas transmission and redistribution. The flowchart is shown in Fig. 2. 


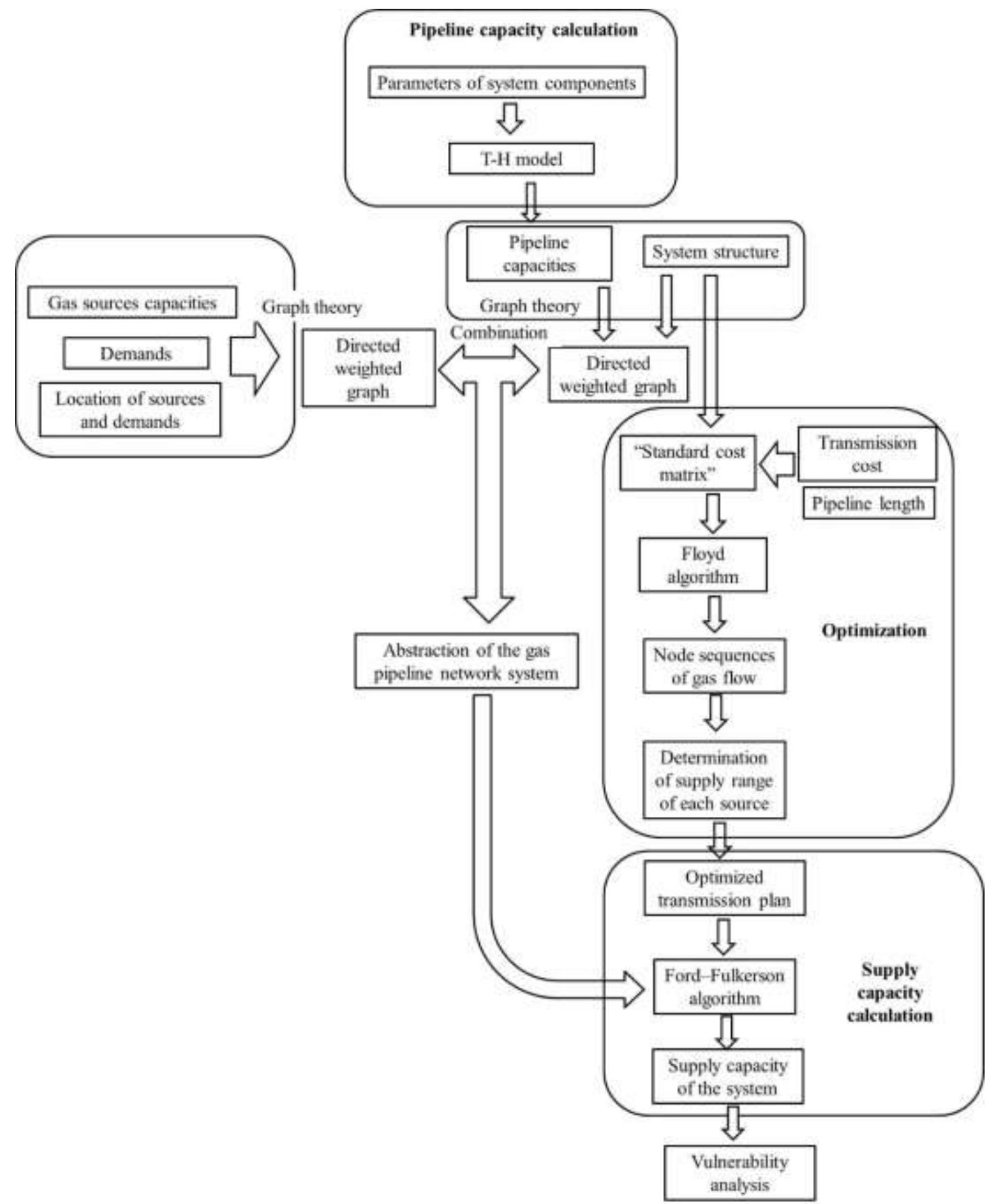

Fig. 2 Flowchart of the capacity/consequence analysis model

\section{Vulnerability analysis of supply service of natural gas pipeline networks}

\subsection{Definition of vulnerability analysis of supply service}

Vulnerability analysis of supply service aims at systematically estimating the negative consequences from strains imposed on a natural gas "supply-transmission-demand" system, and 
identifying system weaknesses that may be exploited by previously unimagined or unknown hazards or threats. In vulnerability analysis, the probabilities of the strains imposed on the system are not addressed.

For network transmission systems, a strain can be defined in different ways considering the different sources of hazards and threats. Defining a strain in a concrete way requires knowledge about the aims of the analysis and the characteristics of the hazards (Zio, 2016). Threats to supply service in a natural gas pipeline network system mainly include degradation of transmission capacities of the pipelines, drop of supply capacities of gas sources and increase of demands. Therefore, the strains in this paper are defined as failures of pipelines, sudden drops of supply capacities of sources and sudden rises of demands. The magnitude of the strains are represented as the number of failed pipelines, degree of capacity drops and degree of demand rises. The impact of the strains are calculated by the modeldeveloped in Section 2.

The vulnerability analysis of gas supply service includes global vulnerability analysis, robustness analysis of demand sites and critical pipeline analysis. The robustness analysis of demand sites is proposed especially for natural gas pipeline network systems, considering that each demand site in the system plays an important role in society and economy, e.g., gate stations of city distribution networks, power plants, factories, etc.

\subsection{Global vulnerability analysis of gas supply service}

Global vulnerability analysis aims at evaluating the capacity of the natural gas pipeline network system to withstand the strains and to estimate the potential negative consequences [10]. The analysis is carried out by imposing strains of increasing magnitude on the system.

According to Section 3.1, the strains come from pipelines, gas sources and demands. Their 
ways to affect the supply service is different, which should be reflected in the analysis. When pipeline failure is taken as the strain, we need to focus on the differences of consequences of failures of different pipelines or pipelines combinations. If the magnitude $N$ (here $N$ represents the number of failed pipelines, as the magnitude of the strain) is small, all the possible scenarios will be calculated. However, for large numbers of failed pipelines, only a partial set (e.g., 5 million random sample scenarios) are considered for system vulnerability analysis, to limit the computation burden. When the sudden drop of capacities of the sources is taken as the strain, global vulnerability analysis is performed by decreasing the level of capacity of all the gas sources. The analysis of vulnerability, caused by demand rise, is performed by increasing the demands of all the customers step by step, because the demand fluctuation of different customers often occurs together due to external causes and we focus on severe conditions.

\subsection{Robustness analysis of gas supply service at demand sites}

Besides the systematic analysis of system performance under strains for the natural gas pipeline network systems, one should also analyze the differences of the capacities in demand sites to withstand the strains. Eách demand site plays an important role, for example, gate stations of gas distribution networks of cities. In this part, we analyze their differences to withstand the degradation of the transmission capacity of the pipeline network, based on parts of the results of the global vulnerability analysis in Section 3.2.

To quantify this, the index average level of unsatisfied demand (ALUD) is originally introduced here:

$$
\operatorname{ALUD}_{m}=\frac{\sum_{i=1}^{N} \frac{\text { Demand }_{m}-\text { capacity }_{m}^{i}}{\text { Demand }_{m}}}{N}=1-\frac{1}{N} \sum_{i=1}^{N} \frac{\text { a apacity }_{m}^{i}}{\text { Demand }_{m}}
$$


In equation 2, $A L U D_{m}$ represents the average level of unsatisfied demand at demand site $m$ under a strain of magnitude $k$; Demand $m$ represents the demand of demand site $m$ in MCM/d; capacity $_{m}^{i}$ is the supply capacity at demand site $m$ under scenario $i$ in MCM/d; $N$ represents the number of scenarios under a strain of magnitude $k$. All the inputs are obtained from the results in Section 3.2.

In this work, the supply capacities at demand sites are solved as a "multiple sources and sinks" max-flow problem, by the Ford-Fulkerson algorithm introduced in Section 2.4. By this method, we can estimate the amount of gas which can be transported to every demand site, in different system conditions.

In Equation 2, the capacity is the amount of gas which can be provided to the customers. This is because the gas transmission plan will change when the network configuration changes, according to the optimization algorithm (in Section 2.3). And, the max-flow algorithm of gas redistribution is performed based on the limitations of gas suppliers and the pipeline network transmission capacities under different conditions.

By observing the trend of $A L U D$ with the increase of strain magnitude (number of failed pipelines), we can qualitatively estimate the robustness of the demand site: a smooth incline means a strong robustness. Further, to quantifying robustness, the index supply service robustness $(S S R)$ is proposed (equation 3):

$$
S S R_{m}=\frac{n}{N_{-} \text {pipelines }}
$$

$S S R_{m}$ represents the supply service robustness at demand site $m$; $N \_$pipelines represents the total number of pipelines in the system; $n$ represents the magnitude $k$ of the strain under which the $A L U D$ of demand site $m$ reaches the tolerable level. A higher SSR means a stronger robustness. 
When SRR equals 1, the target demand site will never reach the lower limit.

To further analyze the reason of the difference, graph theory is applied. From the graph theory perspective, the service robustness of demand site can be converted to the connectivity with other nodes under pipeline failures. Generally, in graph theory, the average path length and topology efficiency are applied to analyze this kind of problem [54], [55]. Average path lengh is used to measure the difference between two nodes in the network. Topology efficiency is used to quantify the transmission efficency between nodes. Both of them are capable to reflect the fault-tolerant ability of a network system. In this paper, we use both the average path length and the topology efficiency of every demand site to quantify their robustness of supply service from a gragh theory perspective. Then, the results are compared with the value of SSR to verify the correctness of the proposed method.

The average path and topology efficiency are given as:

$$
\begin{gathered}
L_{i}=\frac{1}{N_{\text {node }}\left(N_{\text {node }}-1\right)} \sum_{i \neq j} d_{i j}(4) \\
E_{i}=\frac{1}{N_{\text {node }}\left(N_{\text {node }}-1\right)} \sum_{i \neq j} \frac{1}{d_{i j}}(5)
\end{gathered}
$$

$L_{i}$ represents the average length of demand site $i ; E_{i}$ represents the topology efficiency of demand site $i ; d_{i j}$ represents the lengh of the shortest path between demand site $i$ and node $j ; N_{\text {node }}$ represents the number of nodes in the system。

\subsection{Critical pipeline analysis of gas supply service}

In a large natural gas pipeline network, because of its structure complexity, there may be some unknown, perhaps previously unimagined system weaknesses. Critical pipeline analysis focuses on identifying this kind of weakness that contributes to the service vulnerability of the 
system. Other components, such as compressor stations, can also affect the system capacity, but the impacts of their failures will eventually amount to degradation of pipeline capacities. A pipeline, or a combination of pipelines, is a critical component depending on how essential it is for the supply service of the pipeline network system.

In general, the critical component analysis is performed by estimating the consequences of single or multiple component failures, to identify their criticalities [20], [56], [57]. This method is performed exhaustively up to a given number (from 1 to $P$ ) of simultaneous failures, usually the value of $P$ is $3-5$. In this range, every possible failure or simultaneous failures should be simulated, with the model developed in Section 2. This analysis gives a comprehensive picture of the system vulnerability within the number of simultaneous failures considered.

However, in a complex natural gas network, the attack-consequence analysis method needs a large number of simulations, which sometimes can be impossible because of the huge burden of computation. To overcome this problem, in this paper, a flow-based method is applied, which combines flow properties and topology properties of the pipeline network, to measure the criticalities of the pipelines.

Several works have explored the identification of critical arcs in a network by graph theory. On account that the importance of a pipeline depends on its flow capacity and its role in the system topology, an index, named weighted flow capacity rate (WFCR) [39], is chosen to measure the criticalities of the pipelines. WFCR is the combination of flow centrality $(F C)[58]$ and flow capacity rate $(F C R)$ [39]. $F C$ is defined as the sum of flow in pipeline $(i, j)$ for all possible s-d pair max-flow problems divided by the sum of all pairs max flows: $M F_{s d}(i, j)$ represents the flow on pipeline $(i, j)$ when the max flow $M F_{s d}$ is from $s$ to $d$ ( $s$ represents gas sources and $d$ 
represents demand sites). $F C R$ is the sum of the percentages of arc flows to arc capacity for all $s-d$ max flow problems: $c_{i, j}$ represents the capacity of pipeline $(i, j) ; N$ represents the number of $s-d$ pairs.

The $F C$ gives the contribution of pipeline $(i, j)$ to system transmission capacity and $F C R$ accounts for its potential criticality due to capacity limitation. Hence, by weighting each term in equation 7 by the $F C$ value, WFCR gives the expected impact of pipeline $(i, j)$ to the overall system performance:

\section{Case study}

$$
W_{F C R_{i, j}}=\frac{1}{N} \sum_{s, d \in V} F C_{i, j} \frac{M F_{s, d}(i, j)}{c_{i, j}}(8)
$$

We consider a natural gas supply-transmission-demand system, assuming coherent and reasonable data and information of the pipeline network, including customer demands, pipeline parameters, compressor station parameters and gas source capacity. The pipeline network is shown in Fig. 3. Assumptions about locations, capacities and types of gas sources are reported in Table 1, whereas the demands are listed in Table 2. This assumed gas pipeline network is adopted from [19], with some adjustments. 


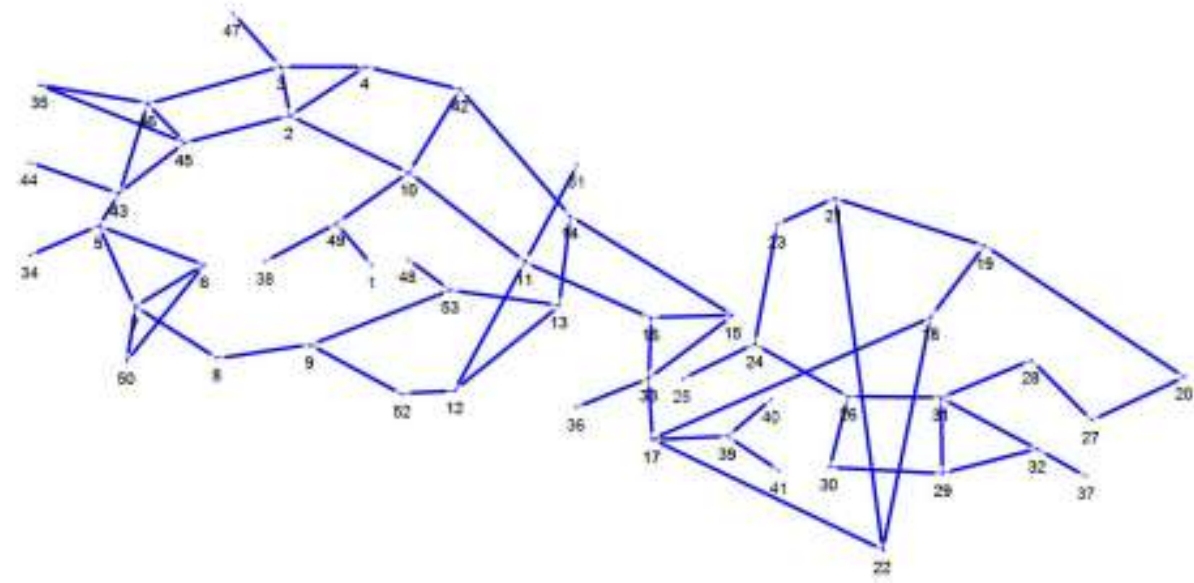

Fig. 3 Topology of the gas network [19]

Table 1 Properties of the gas sources of the gas network

\begin{tabular}{ccc}
\hline Location & Type & Limit (MCM/d) \\
\hline 9 & LNG terminal & 4 \\
10 & Pipeline & 31 \\
15 & LNG terminal & 10 \\
18 & Pipeline & 25 \\
50 & LNG terminal & 7.1 \\
\hline
\end{tabular}

Table 2 Demands of customers of the gas network

\begin{tabular}{cccc}
\hline Location & Demand $(\mathrm{MCM} / \mathrm{d})$ & Location & Demand $(\mathrm{MCM} / \mathrm{d})$ \\
\hline 4 & 1.43 & 34 & 1.00 \\
5 & 1.57 & 35 & 1.00 \\
6 & 1.66 & 36 & 1.74 \\
9 & 1.46 & 37 & 1.30 \\
12 & 4.40 & 38 & 1.00 \\
16 & 1.54 & 40 & 2.00 \\
17 & 0.50 & 41 & 1.40 \\
20 & 1.50 & 42 & 0.50 \\
24 & 1.60 & 44 & 1.06 \\
25 & 1.80 & 46 & 1.82 \\
27 & 2.50 & 47 & 0.68 \\
29 & 2.00 & 48 & 1.17 \\
32 & 0.80 & 49 & 2.00 \\
33 & 0.80 & 51 & 0.98 \\
\hline
\end{tabular}

The values of the lengths of the pipelines are necessary for the consequence analysis model 
(introduced in Section 2) and are listed in Table 3. The overall pipeline network system has been validated by TGNET and the pipeline transmission capacities $\left(Q_{i j}\right)$ are calculated by the model as follows:

$$
\begin{array}{r}
Q_{i j}=\sqrt{\frac{\Delta P_{\max }^{2}}{K_{i j}}}(9) \\
K_{i j}=4.5399 \times 10^{8} \frac{f g Z T}{D^{5}}\left(\frac{P_{n}}{T_{n}}\right)^{2} L(10)
\end{array}
$$

where $\Delta P_{\max }^{2}$ represents the maximal allowable square difference of the pressures at the outlet and inlet nodes of the pipeline $i-j ; D$ is the pipeline diameter; $T$ is the Temperature of the gas; $T_{n}$ is the standard temperature condition; $f$ is the Darcy's friction factor; $g$ is the gravitational acceleration; $Z$ is the gas compressibility; $L$ is the pipeline length. In this paper, the parameter values used are adopted from [19] or assumed by experience and the recommended values in TGNET. The $\Delta P_{\max }^{2}$ is calculated from the data provided in [19].

Table 3 Information of the pipeline lengths for the input of the optimization model

\begin{tabular}{cccccc}
\hline & & Length & & & \\
From & To & & Tength \\
& & $(\mathrm{km})$ & & & \\
& & & & & \\
\hline 1 & 49 & 23.00 & 17 & 22 & 43.00 \\
2 & 3 & 0.01 & 17 & 33 & 43.00 \\
2 & 4 & 32.00 & 17 & 39 & 148.00 \\
2 & 10 & 29.00 & 18 & 19 & 60.00 \\
2 & 45 & 22.00 & 18 & 22 & 0.01 \\
3 & 4 & 32.00 & 19 & 20 & 90.00 \\
3 & 46 & 22.00 & 19 & 21 & 0.01 \\
3 & 47 & 2.00 & 20 & 21 & 90.00 \\
4 & 42 & 5.00 & 20 & 27 & 86.00 \\
4 & 6 & 80.00 & 21 & 22 & 60.00 \\
5 & 7 & 80.00 & 21 & 23 & 86.00 \\
5 & 34 & 30.00 & 23 & 24 & 86.00 \\
5 & 43 & 11.60 & 24 & 25 & 46.00 \\
6 & 7 & 0.01 & 24 & 26 & 100.00 \\
6 & 50 & 200.00 & 26 & 29 & 0.01 \\
7 & 8 & 25.00 & 26 & 31 & 70.00 \\
7 & 50 & 200.00 & 27 & 28 & 50.00 \\
8 & 9 & 162.00 & 28 & 31 & 195.00 \\
9 & 52 & 144.00 & 29 & 30 & 70.00 \\
\hline
\end{tabular}




\begin{tabular}{cccccc}
\hline 9 & 53 & 144.00 & 29 & 31 & 0.01 \\
10 & 11 & 103.00 & 29 & 32 & 60.00 \\
10 & 42 & 34.00 & 31 & 32 & 60.00 \\
10 & 49 & 31.00 & 32 & 37 & 60.00 \\
11 & 12 & 85.00 & 33 & 36 & 200.00 \\
11 & 16 & 62.00 & 35 & 45 & 24.00 \\
11 & 51 & 10.00 & 35 & 46 & 24.00 \\
12 & 13 & 0.01 & 38 & 49 & 106.00 \\
12 & 52 & 30.00 & 39 & 40 & 32.00 \\
13 & 14 & 85.00 & 39 & 41 & 63.00 \\
13 & 53 & 85.00 & 43 & 44 & 1.00 \\
14 & 15 & 122.00 & 43 & 45 & 23.00 \\
14 & 42 & 122.00 & 43 & 46 & 23.00 \\
15 & 16 & 0.01 & 45 & 46 & 0.01 \\
15 & 33 & 24.00 & 48 & 53 & 40.00 \\
16 & 33 & 24.00 & 52 & 53 & 0.01 \\
17 & 18 & 43.00 & & & \\
\hline \multicolumn{7}{c}{} & & & &
\end{tabular}

Global vulnerability analysis of supply/service was performed from three perspectives, according to the three definitions of strains, as introduced in Section 3.2. The negative consequences are measured in terms of supply capacities (or shortages) and number of unsatisfied customers.

The results of the "pipeline-failure based" analysis are shown in Figs. 4-6. In this part, the failure of a pipeline is considered as a $100 \%$ transmission-capacity loss. For the analysis, an increasing number of pipelines are randomly removed and the consequences are estimated by the model developed in Section 2. The results in Figs. 4-6 provide a relatively comprehensive picture of the negative consequences under different levels of the strains. On average, a large fraction of pipelines have to be damaged to produce significant losses of supply service. For example, when 10 pipelines are randomly failed, there is only a $15 \%$ drop of supply capacity and $20 \%$ affected demand sites. This indicates that this natural gas supply-transmission-demand network is a 
relatively robust system and many of these pipelines are not critical for the gas supply service.

However, the maximum and minimum values show a large variation, which is caused by a few highly critical pipelines.

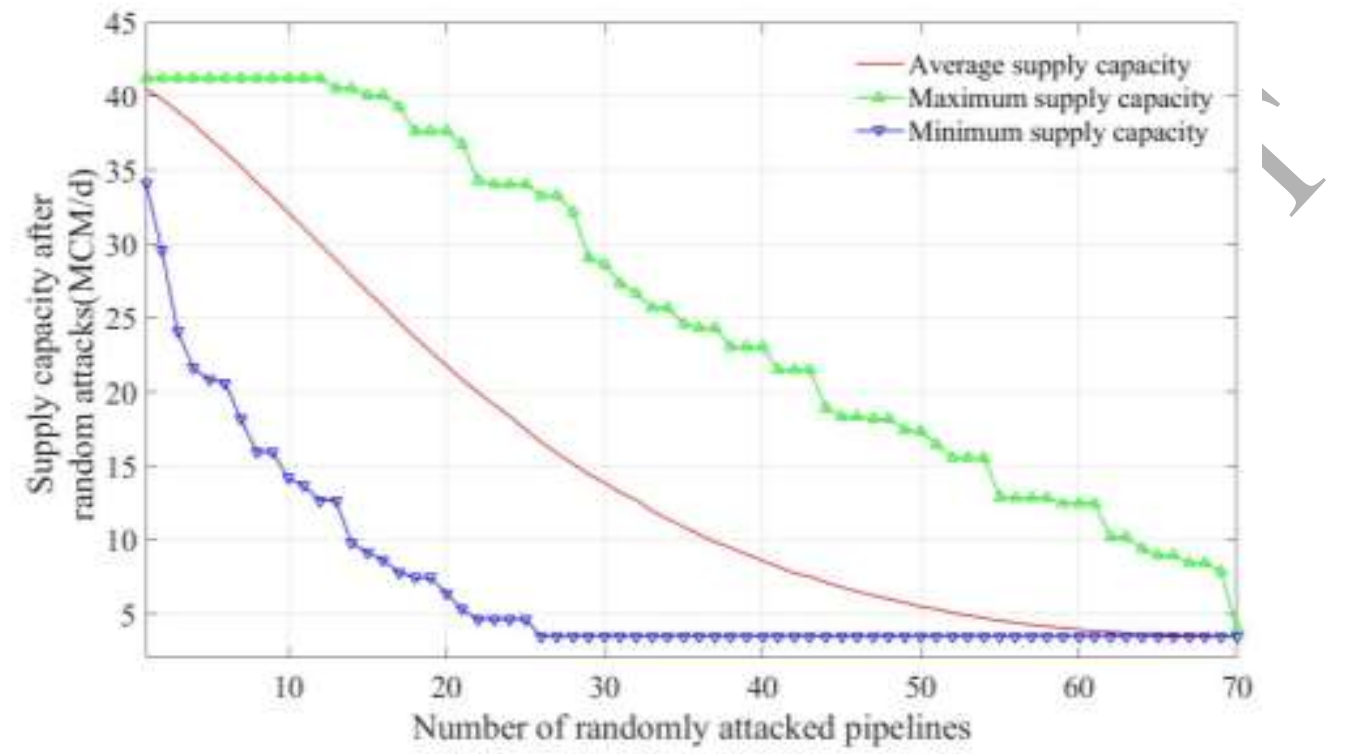

Fig.4. Results of global vulnerability analysis in terms of system supply capacity

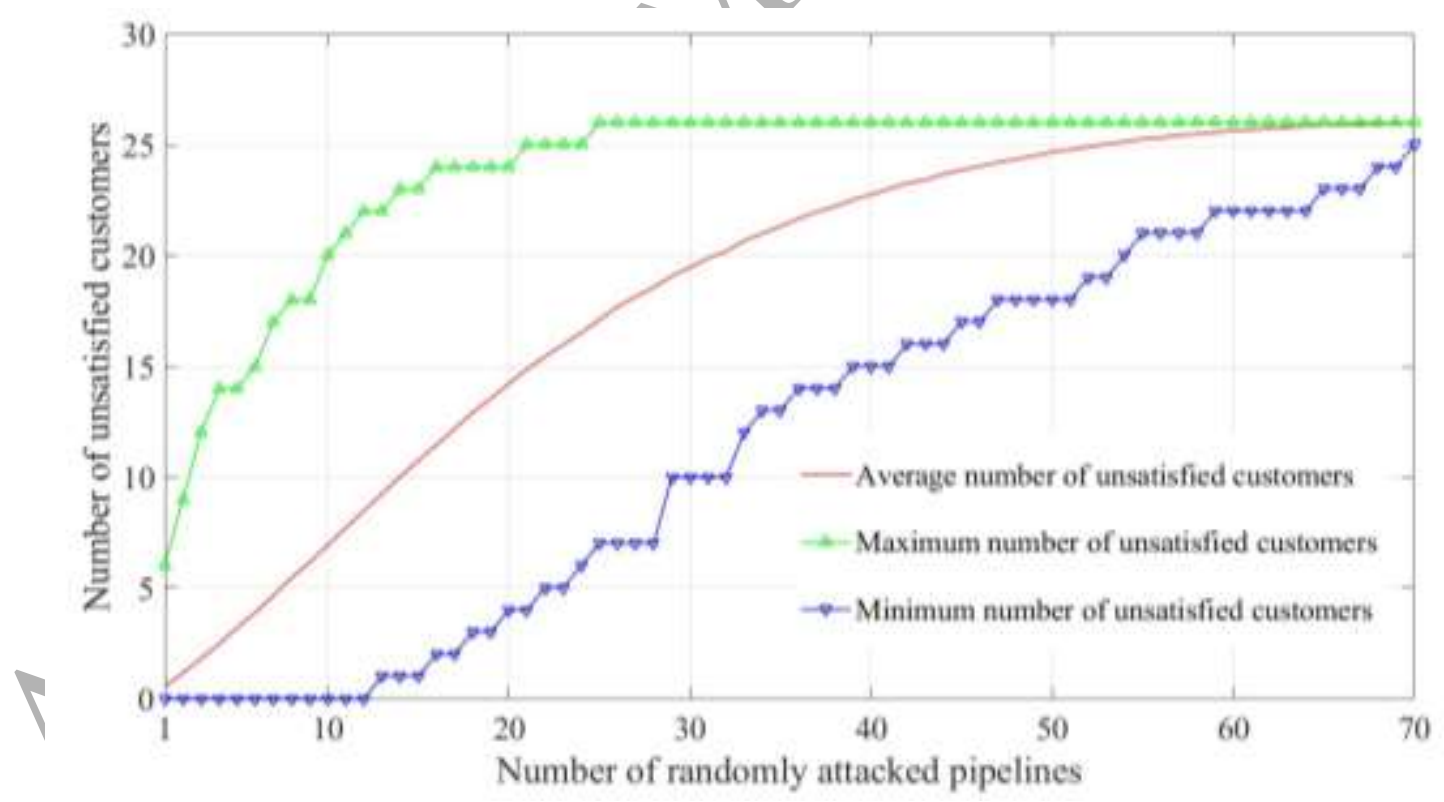

Fig.5. Results of global vulnerability analysis in terms of the amounts of unsatisfied customers

In general, operators and managers are more concerned about the system's ability to withstand the failures of pipelines. The ability to maintain the system capacity within a tolerable 
range, even under unpredictable attacks, is quantified by the probability of supply capacity lower than a tolerable level. The trends of the index values, under different criteria of tolerable level (40 MCM/d, $35 \mathrm{MCM} / \mathrm{d}, 30 \mathrm{MCM} / \mathrm{d}$ ), along with increasing magnitudes of strains are shown in Fig. 6. From Fig.6, considering the tolerable level of $30 \mathrm{MCM} / \mathrm{d}$, the ability to withstand strains, or to maintain a certain capacity, is good up to 10 pipelines; then, the supply capacity of the system begins to collapse. By comparing the curves of different tolerable levels, we can see that the system presents different vulnerability performances. Hence, the requirement of customers should be claimed clearly.

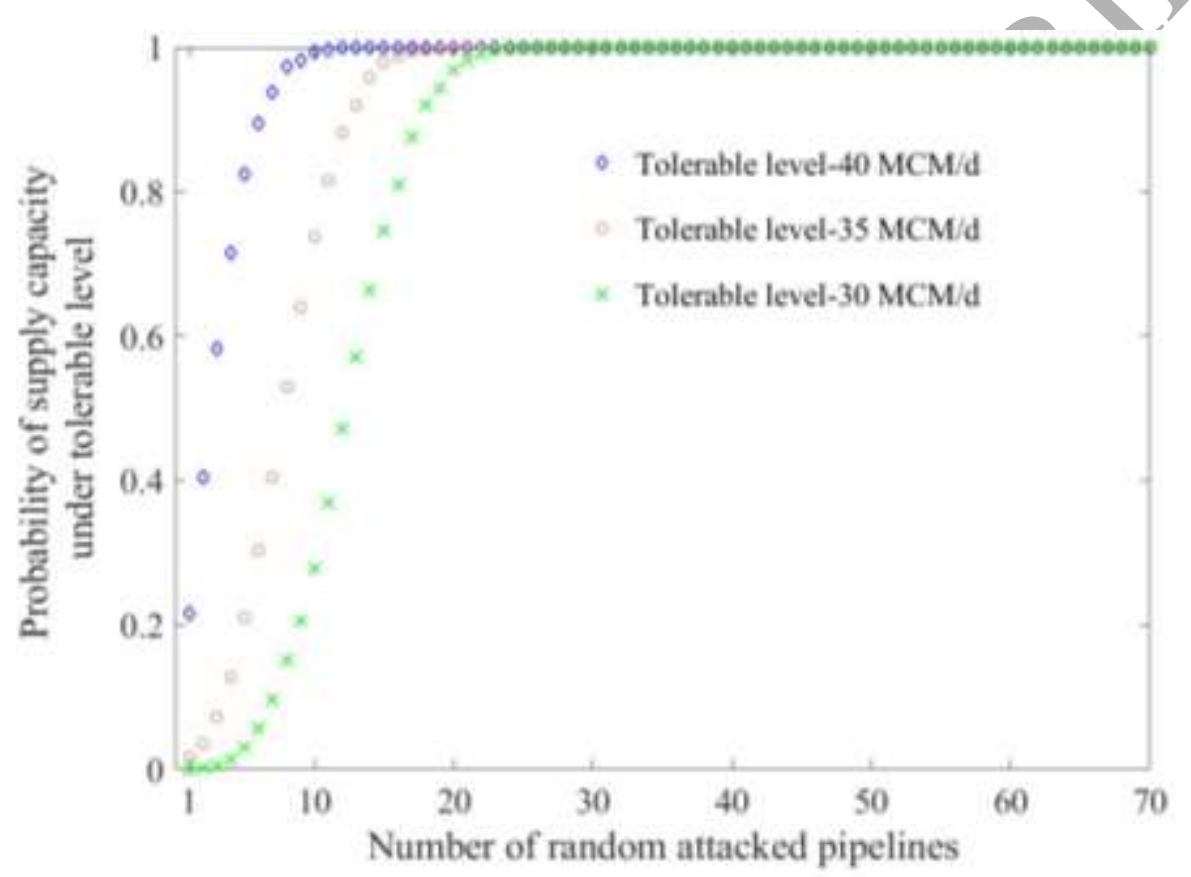

Fig.6. Global vulnerability analysis with respect to PSCUTL

Considering a sudden drop of supply capacities of sources as the strain, as introduced in Section 3.2, the results of global vulnerability analysis of supply service are shown in Figs. 7-8. The analysis was performed by reducing the capacities of all the sources step by step and simulating all the scenarios by the model developed in Section 2. By observing Figs.7-8, we can conclude that the system supply capacity presents good robustness when the drop is within $30 \%$ of the normal capacity of the gas sources. The robustness comes from redundancy of gas sources and system flexibility due to the network structure. However, when the total source capacity drops to 
$55 \%$ of the normal condition, the system is sensitive to the change. Besides, the "jumps" in Fig. 8 show a relatively strong dependence of the local customers on some specific sources (even if the customers can get gas from also the other sources), which means that the flexibility of this network system should be further improved.

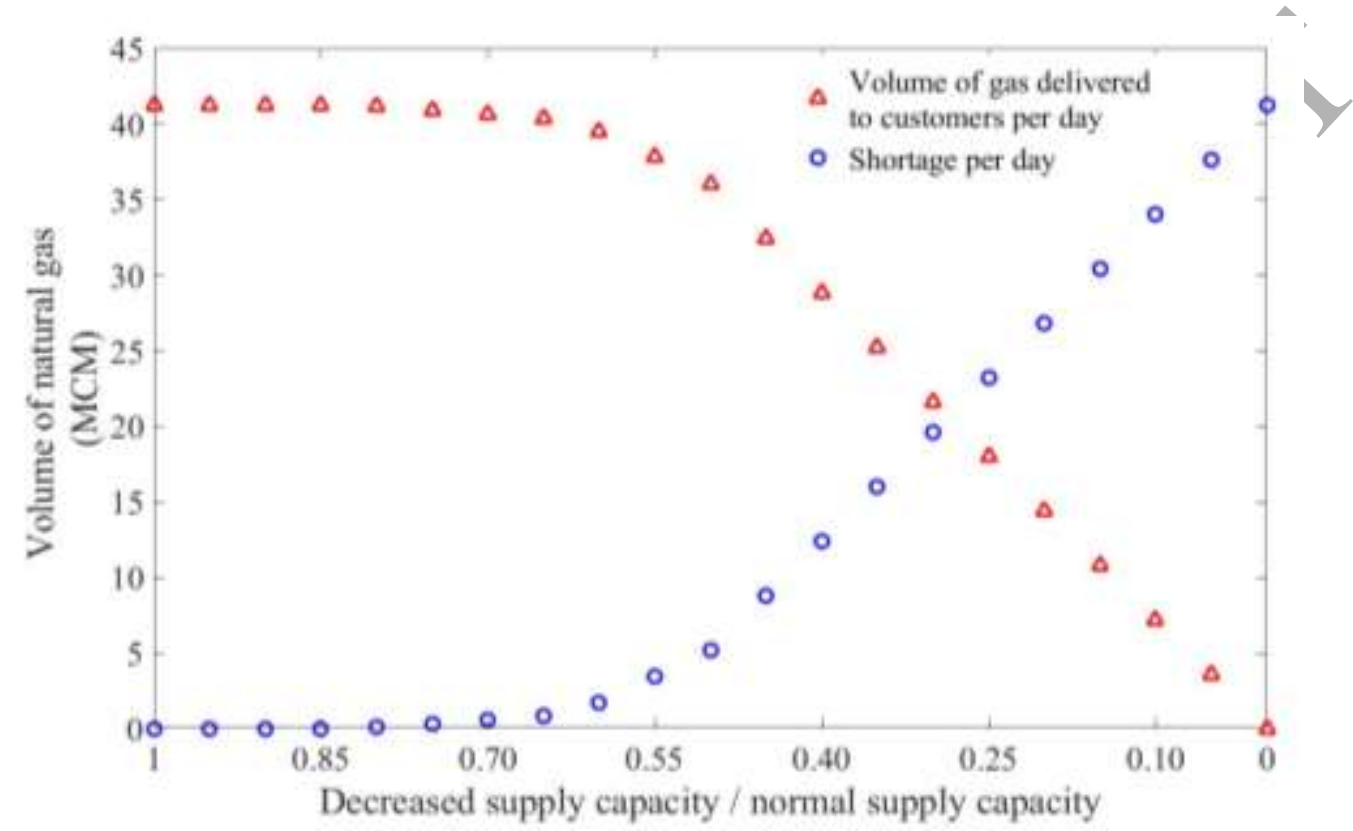

Fig.7. Global vulnerability analysis based on degeneration of supply capacities of sources

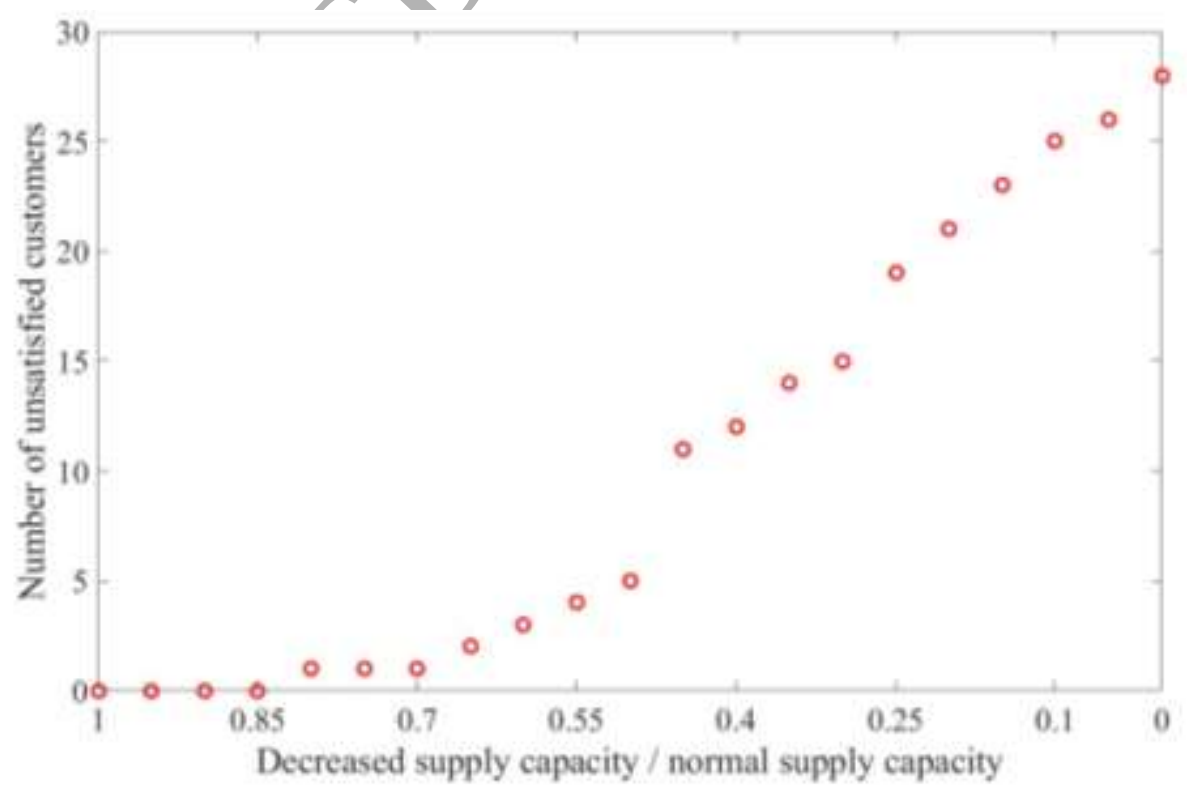

Fig.8. Global vulnerability analysis based on degeneration of supply capacities of sources

From Figs.9-10, we can observe the system performance and consequences under the strain 
of increase of total demands. In Fig. 9, we can observe the trend of the overall system performance of supply, for increasing demands of all customers. The performance is measured from the perspectives of global shortage of gas and global supply capacity. Before the demands increase to $130 \%$ of the normal demands, the supply capacity increases stably to fulfill the increasing demands and the system shows robustness. In this stage, both the supply capacities of supply sources and the pipeline network transmission capacity are sufficient to support the increasing demands. When the demands increase to $130 \%-180 \%$ of the normal demands, shortage emerges and increases slowly along with the increase of demands. In this range, system/is relatively robust but the redundancy offered by the pipeline network transmission capacity is running off. However, when the actual demands are more than $180 \%$ of the normal demands, shortage increases rapidly and the system is vulnerable to the strain of the increase of the demands.

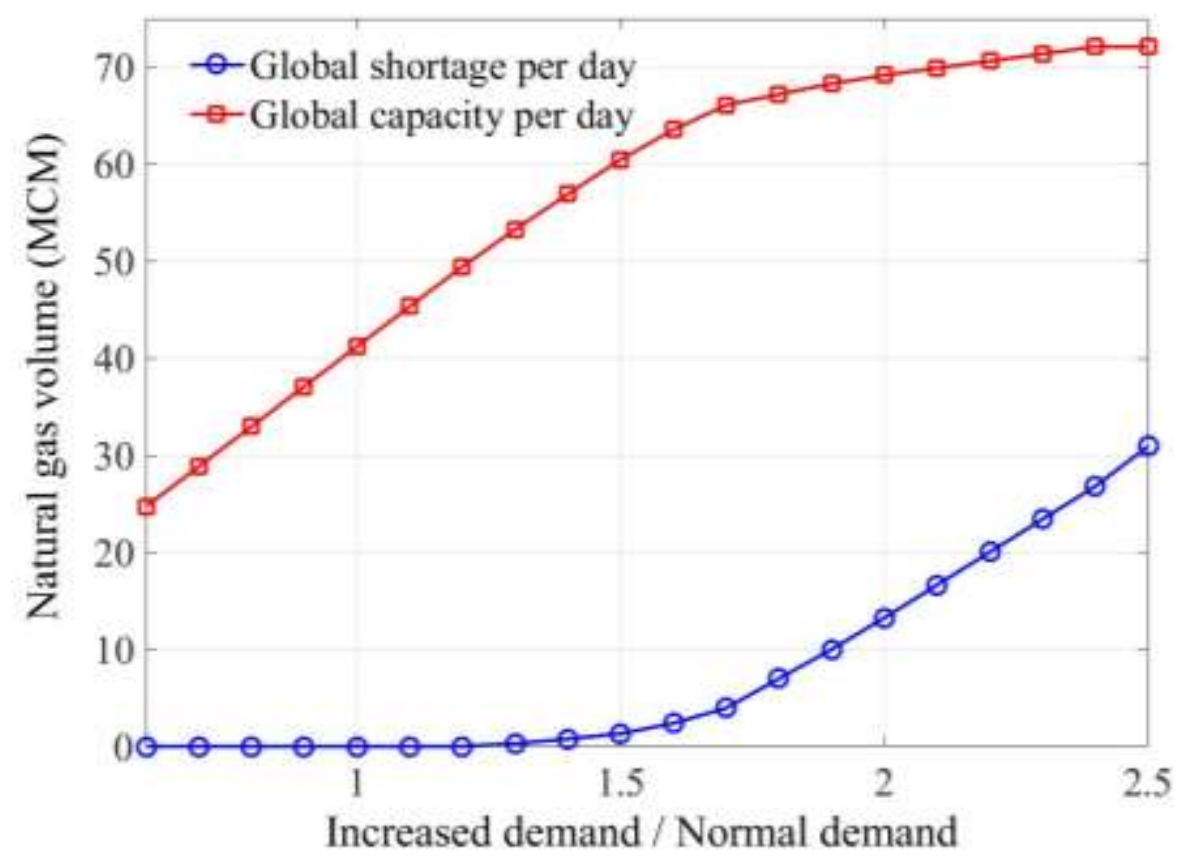

Fig.9. Global vulnerability analysis based on increase of demands 


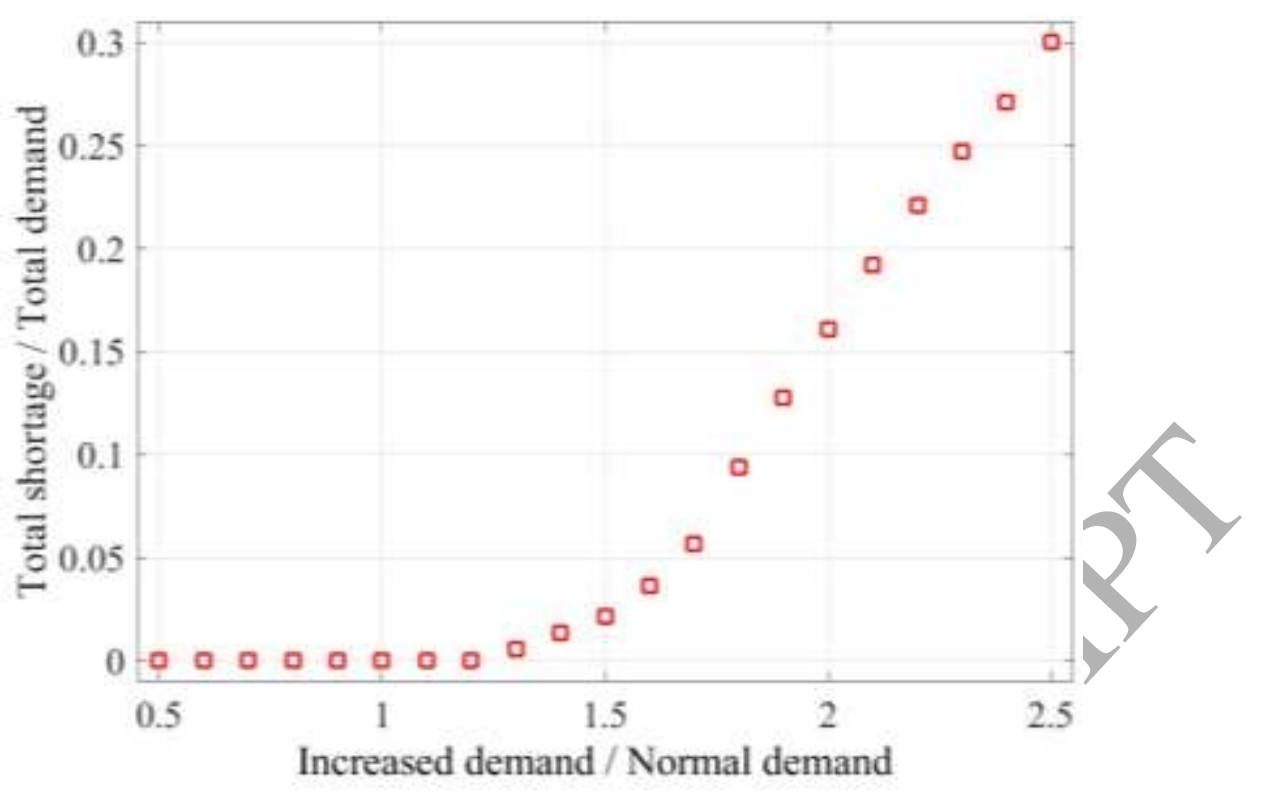

Fig.10. Global vulnerability analysis based on increase of demands

\subsection{Results of supply service robustness at demand sites}

As introduced in Section 3.3, to analyze the ability of each demand site to withstand the strain of system transmission capacity degeneration, the $A L U D$ of each demand site was calculated (equation 5) under different magnitudes (number of failed pipelines) of the strain. The results are shown in Fig.11. Although the values of $A L U D$ of every demand site are increasing, their trends are different: some increase rapidly and some increase slowly. The sharp curves mean that these demand sites are sensitive (vulnerable) to the strain and the gentle curves are opposite. To measure this ability, SSR of each demand site was calculated by equation 6 and the results are listed in Table.4. 


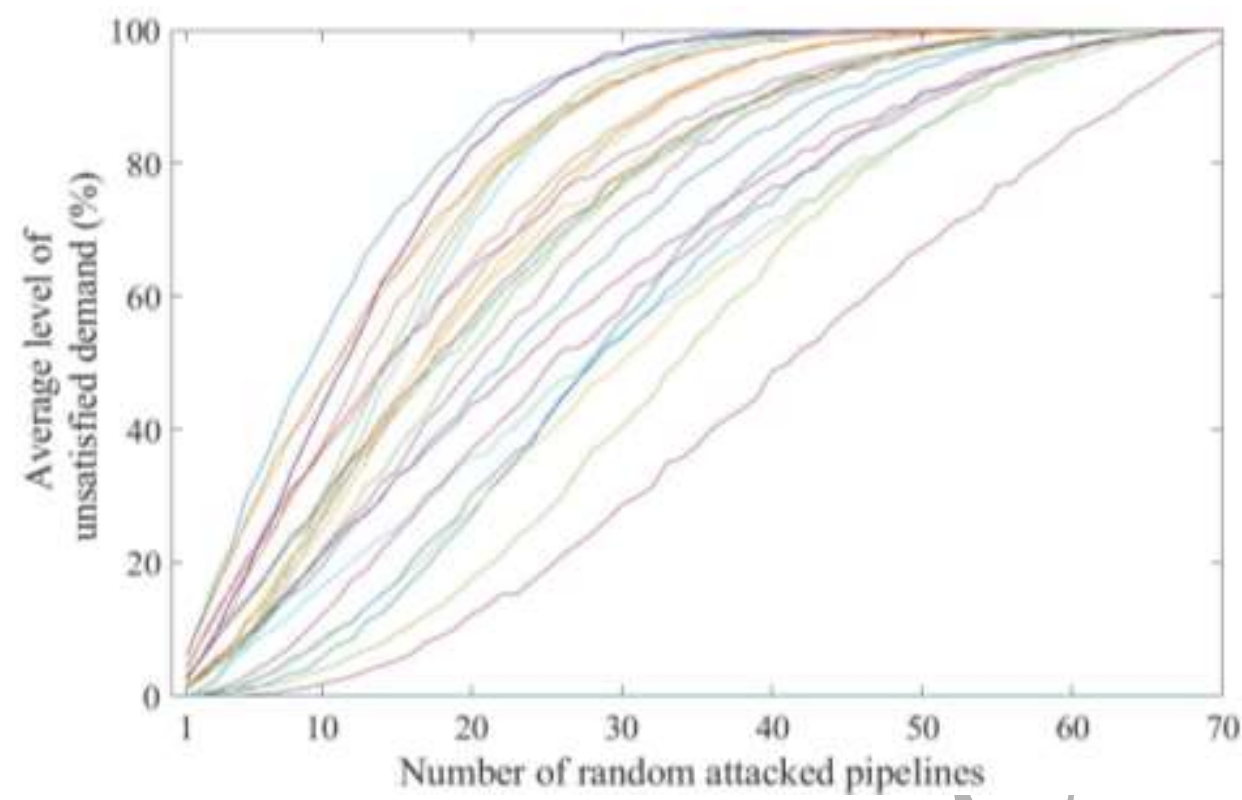

Fig.11. ALUD of the demand sites under different levels of strains

Table 4 SSR of the demand sites

\begin{tabular}{cccc}
\hline Location & SSR & Location & SSR \\
\hline 4 & 0.5571 & 34 & 0.2429 \\
5 & 0.3143 & 35 & 0.3857 \\
6 & 0.6571 \\
9 & 1.0000 & 36 & 0.4286 \\
12 & 0.6571 & 37 & 0.2712 \\
16 & 0.6429 & 38 & 0.4429 \\
17 & 0.8143 & 40 & 0.4429 \\
20 & 0.6143 & 41 & 0.4429 \\
24 & 0.3714 & 42 & 0.5143 \\
25 & 0.3000 & 44 & 0.3000 \\
27 & 0.4714 & 46 & 0.4000 \\
29 & 0.3143 & 47 & 0.4143 \\
32 & 0.3286 & 48 & 0.4571 \\
33 & 0.6143 & 49 & 1.0000 \\
& & 51 & 0.5857 \\
\hline
\end{tabular}

In natural gas transmission systems, all the demand sites are important because each of them

contributes to a specific important function of society and economy, e.g. distribution networks of

cities, power plants, factories, etc. Therefore, there is a critical problem on how to enhance the robustness of the demand sites to withstand the unexpected events.

In Section 3.2, two indices, average path length $(L)$ and global efficiency $(E)$ of the demand 
sites, have been introduced. The indices of every demand site were calculated for the case study of interest and listed in Table 5.

Table 5 Average path length and global efficiency of the demand sites

\begin{tabular}{cccccc}
\hline Location & $L$ & $E$ & Location & $L$ & $E$ \\
\hline 4 & 4.8889 & 0.2796 & 34 & 6.0185 & 0.2126 \\
5 & 5.0556 & 0.2823 & 35 & 5.7407 & 0.2341 \\
6 & 4.6111 & 0.2817 & 36 & 5.1296 & 0.2350 \\
9 & 3.9259 & 0.3281 & 37 & 8.4815 & 0.1625 \\
12 & 4.8148 & 0.2859 & 38 & 5.4444 & 0.2225 \\
16 & 4.2593 & 0.3064 & 40 & 5.8519 & 0.2055 \\
17 & 4.0000 & 0.3237 & 41 & 5.8519 & 0.2055 \\
20 & 4.5926 & 0.2734 & 42 & 4.2963 & 0.3093 \\
24 & 5.7963 & 0.2412 & 44 & 6.3704 & 0.2094 \\
25 & 6.7593 & 0.1890 & 46 & 5.4815 & 0.2738 \\
27 & 5.2963 & 0.2391 & 47 & 5.8333 & 0.2187 \\
29 & 7.5185 & 0.2051 & 48 & 5.6296 & 0.2194 \\
32 & 7.5185 & 0.2051 & 49 & 3.9815 & 0.3157 \\
33 & 4.1667 & 0.3162 & 51 & 5.1296 & 0.2413 \\
\hline
\end{tabular}

To investigate the robustness of the demand sites, the SSR-E (Fig. 12) and $S S R-L^{-1}$ (Fig. 13) were drawn, and the correlation coefficients between $S S R$ and $E, L$ were calculated, respectively (Table 6). From these results, we can conclude that there are strong correlations between SSR and $E, L$. 


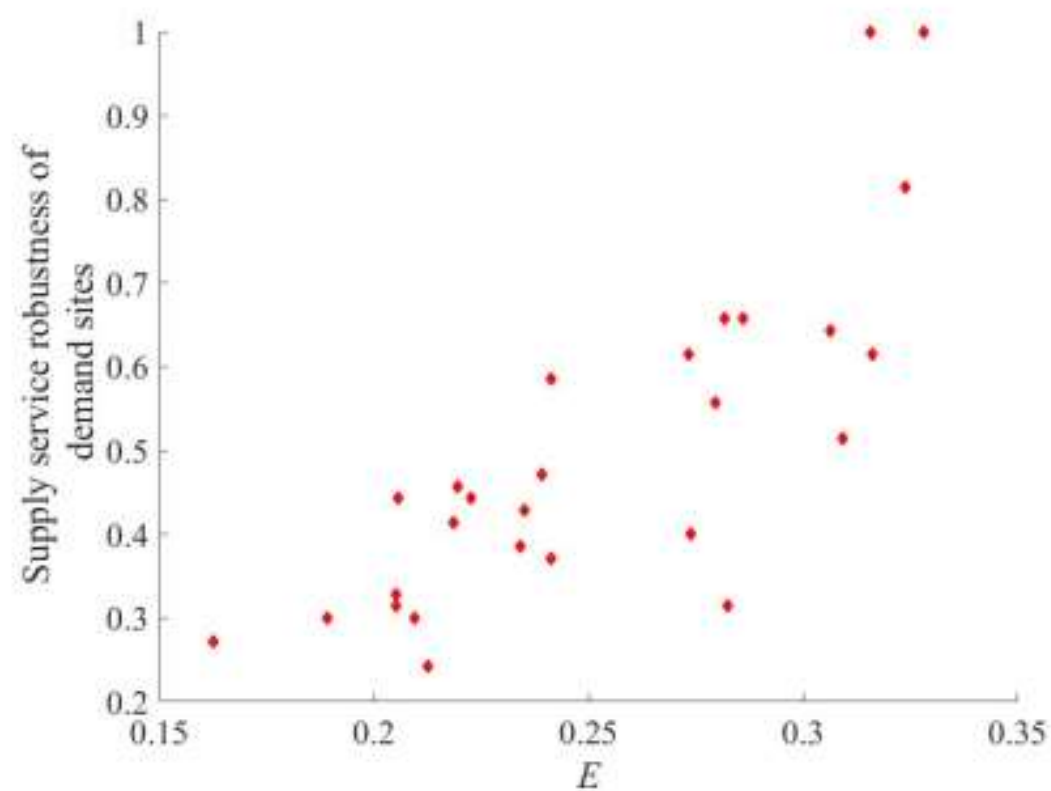

Fig.12. SSR-E plot

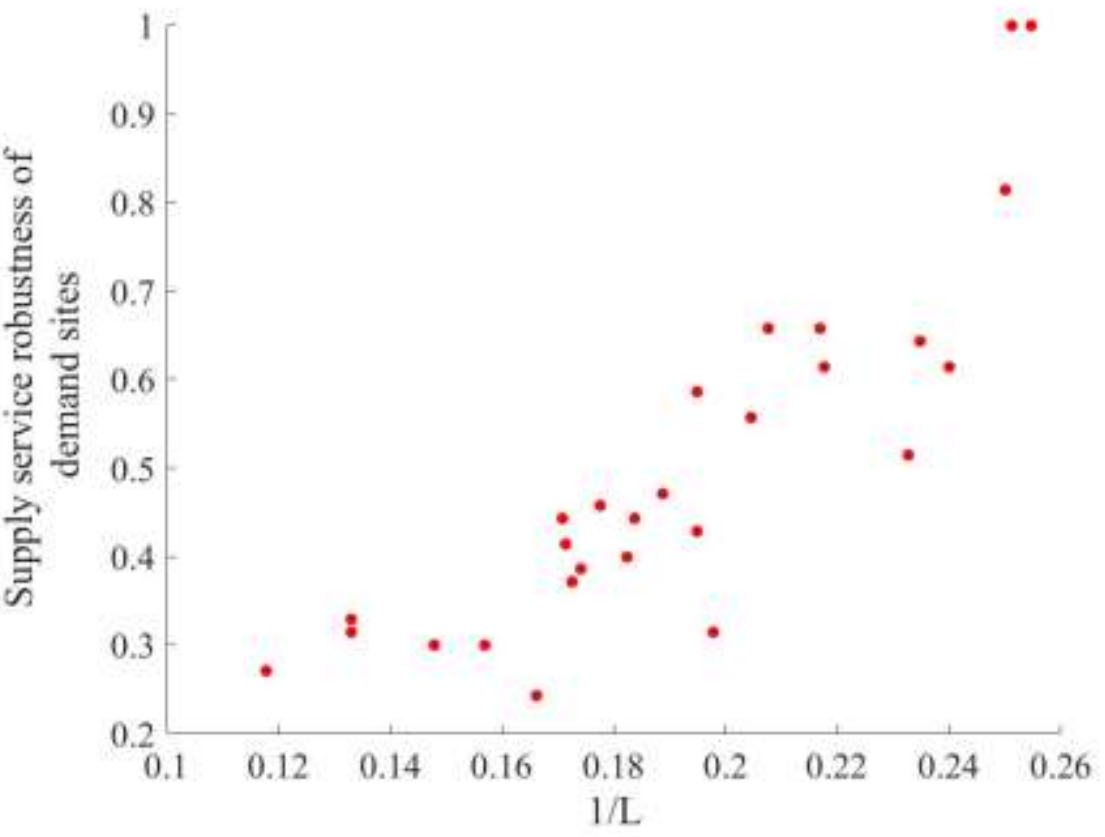

Fig.13. SSR- $L^{-1}$ plot

Table 6 Correlation coefficient of SSR-E and SSR-L

\begin{tabular}{ccc}
\hline & $E$ & $L^{-1}$ \\
\hline$S S R$ & 0.7969 & 0.8644 \\
\hline
\end{tabular}

\subsection{Results of critical component analysis}


As introduced in Section 3.4, to estimate the criticalities of pipelines, an overview of consequences of failures of pipelines and pipelines combinations have been analyzed. The exhaustive analyses were performed for $\mathrm{N}-1$ to $\mathrm{N}-3$ simultaneous failures, i.e. only covering a small portion of the potential number of failed pipelines in the global vulnerability analysis. All the possible consequences are sorted from high to low and presented in Fig.14. The pipelines or the combinations with high consequences have relative high criticalities.

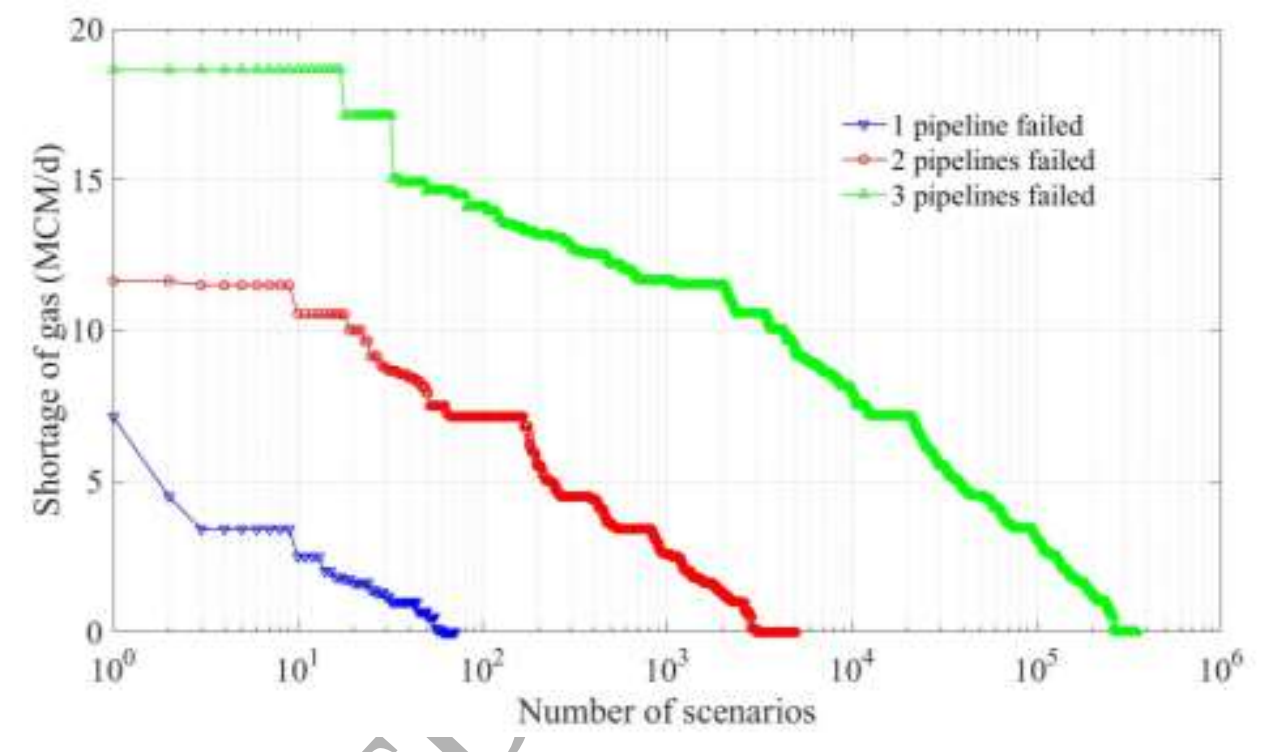

Fig.14. Distribution of shortage for $N-1, N-2, N-3$ simultaneous failures

However, for a pipeline network with thousands of pipelines, the direct method needs a large number of simulations and it is impossible to perform exhaustive analyses under high-order scenarios. Hence, in Section 3.4, a hybrid index, named weighted flow capacity rate (WFCR) in equation 5, is proposed to measure the criticalities of pipelines. The pipelines were sorted according to $W F C R$, from highest to lowest, in Table 7. For a further comparison analysis, $F C$, the measurement of contributions of pipelines to system transmission capacity, and FCR, the measurement of the pipelines potential criticality due to capacity limitation, were also calculated. The pipeline criticalities sequences based on $F C R$ and $F C$ are also listed in Table 7. 
Table 7 Pipeline ranking according to importance calculation based on different methods

\begin{tabular}{|c|c|c|c|c|c|}
\hline \multicolumn{2}{|c|}{$F C$} & \multicolumn{2}{|c|}{$F C R$} & \multicolumn{2}{|c|}{$W F C R$} \\
\hline From & To & From & To & From & To \\
\hline 10 & 2 & 10 & 2 & 10 & 2 \\
\hline 16 & 11 & 18 & 19 & 10 & 11 \\
\hline 18 & 19 & 17 & 39 & 10 & 49 \\
\hline 10 & 11 & 43 & 5 & 18 & 19 \\
\hline 10 & 49 & 16 & 33 & 16 & 11 \\
\hline 11 & 12 & 23 & 24 & 16 & 33 \\
\hline 19 & 20 & 31 & 29 & 11 & 51 \\
\hline 16 & 33 & 10 & 11 & 11 & 12 \\
\hline 2 & 3 & 20 & 27 & 20 & 27 \\
\hline 20 & 27 & 18 & 22 & 17 & 39 \\
\hline 2 & 45 & 9 & 52 & 23 & 24 \\
\hline 18 & 22 & 9 & 53 & 18 & 22 \\
\hline 11 & 51 & 11 & 51 & 10 & 42 \\
\hline 10 & 42 & 14 & 13 & 18 & 17 \\
\hline 18 & 17 & 31 & 32 & 33 & 17 \\
\hline 33 & 17 & 39 & 40 & 43 & 5 \\
\hline 19 & 21 & 46 & 43 & 19 & 21 \\
\hline 21 & 23 & 33 & 17 & 21 & 23 \\
\hline 23 & 24 & 10 & 42 & 2 & 4 \\
\hline 17 & 39 & 18 & 17 & 3 & 47 \\
\hline 3 & 46 & 22 & 21 & 50 & 6 \\
\hline 27 & 28 & & 21 & 31 & 29 \\
\hline 28 & & $21^{\prime}$ & 23 & 22 & 21 \\
\hline 45 & & 15 & 33 & 9 & 53 \\
\hline 13 & & 29 & 32 & 14 & 13 \\
\hline 43 & & 2 & 45 & 39 & 40 \\
\hline 31 & 29 & 16 & 11 & 3 & 46 \\
\hline 21 & 20 & 21 & 20 & 2 & 45 \\
\hline 22 & 21 & 10 & 49 & 29 & 32 \\
\hline 2 & 4 & 2 & 4 & 2 & 3 \\
\hline 3 & 47 & 3 & 47 & 21 & 20 \\
\hline 22 & 17 & 5 & 34 & 15 & 33 \\
\hline 50 & 6 & 30 & 29 & 46 & 35 \\
\hline 9 & 53 & 32 & 37 & 19 & 20 \\
\hline 14 & 13 & 33 & 36 & 24 & 25 \\
\hline
\end{tabular}

In Table 7, the pipelines with higher $F C$ values have heavier burdens in the process of gas transmission in the pipeline network. The pipelines which are high-ranked by $F C R$ are more prone 
to become potential bottlenecks because of the low margins between their loads and capacities.

The WFCR index combines the concepts of both $F C$ and $F C R$, and the pipelines with higher WFCR values are more critical for the gas supply service of the pipeline network. We notice that pipelines connecting paralell pipelines and with short length but relatively high capacity (like pipeline 15-16), may have high criricalities, because that the flow-based measures of criticality directly depends on the value of $\sum_{s, d \in V} M F_{s d}(i, j)$.

The effectiveness of the proposed method was verified by a "random attack \& preparedness policy" simulation. In the "random attack \& preparedness policy" simulation, firstly, random attacks were performed on the system. The numbers of random attacks of N-1, N-2 and N-3 simultaneous failures are 100, 10000 and 500000, respectively. When the pipelines are sampled, their capacities will be reduced to zero. Secondly, six kinds of preparedness policies were carried out. The first policy selects no pipeline to harden. The second policy randomly selects $15 \%$ of the pipelines for hardening. The $3^{\text {rd }}-5^{\text {th }}$ policies select the top $15 \%$ critical pipelines based on $F C$, FCR and WFCR, to harden, respectively. The $6^{\text {th }}$ policy selects the top $15 \%$ critical pipelines or pipeline combinations, according to the direct consequences in Fig. 16. In the preparedness policies, the selected pipelines will maintain $70 \%$ of their normal capacities after attack. The consequences were represented by "100\%×( shortage /normal demand)". The results of the "random attack \& preparedness policy" simulations are shown in Figs.15-17 in the form of box plots. Supplementary statistic information, i.e., mean value (Mean) and variance (Var) of the consequences of different preparedness policies, is listed in Table 8. 


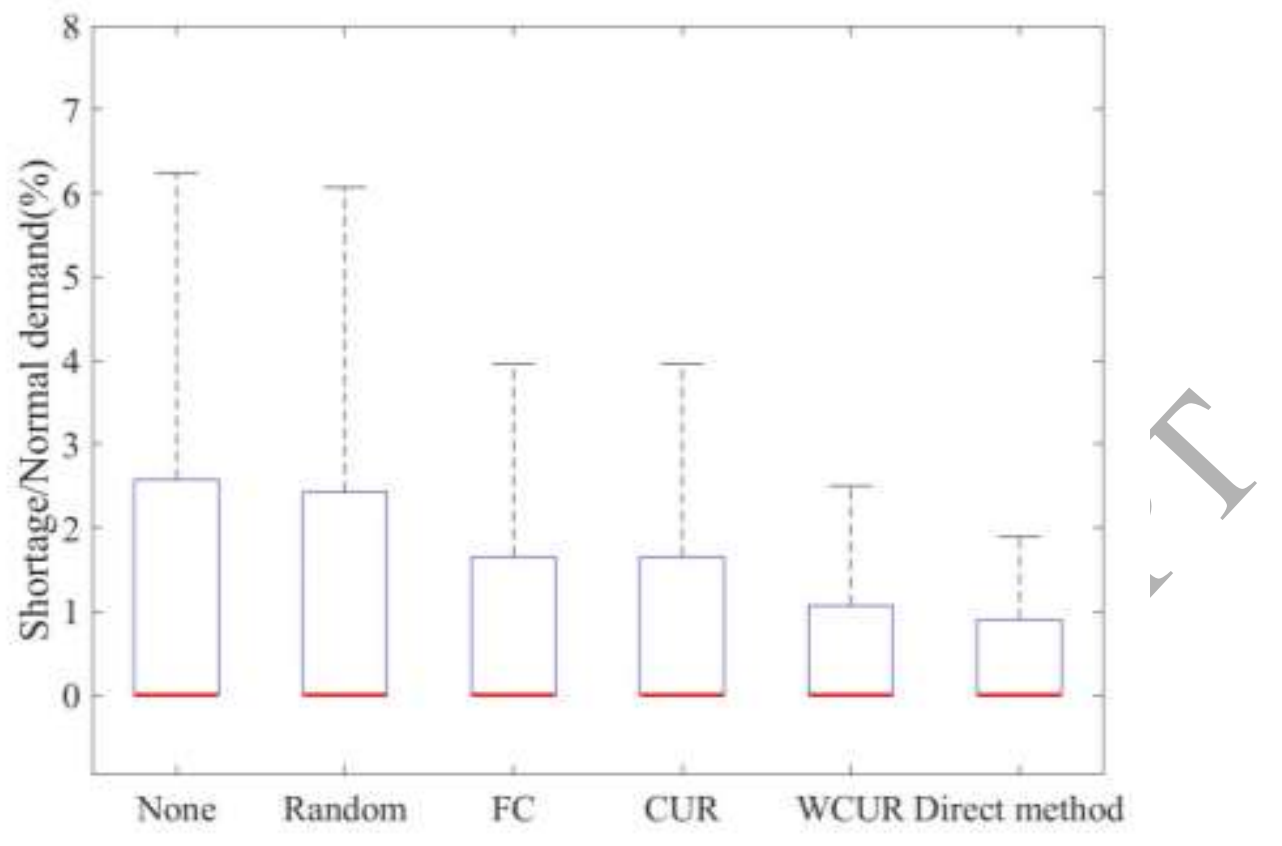

Fig.15. Global vulnerability by different preparedness policies (1 pipeline failure)

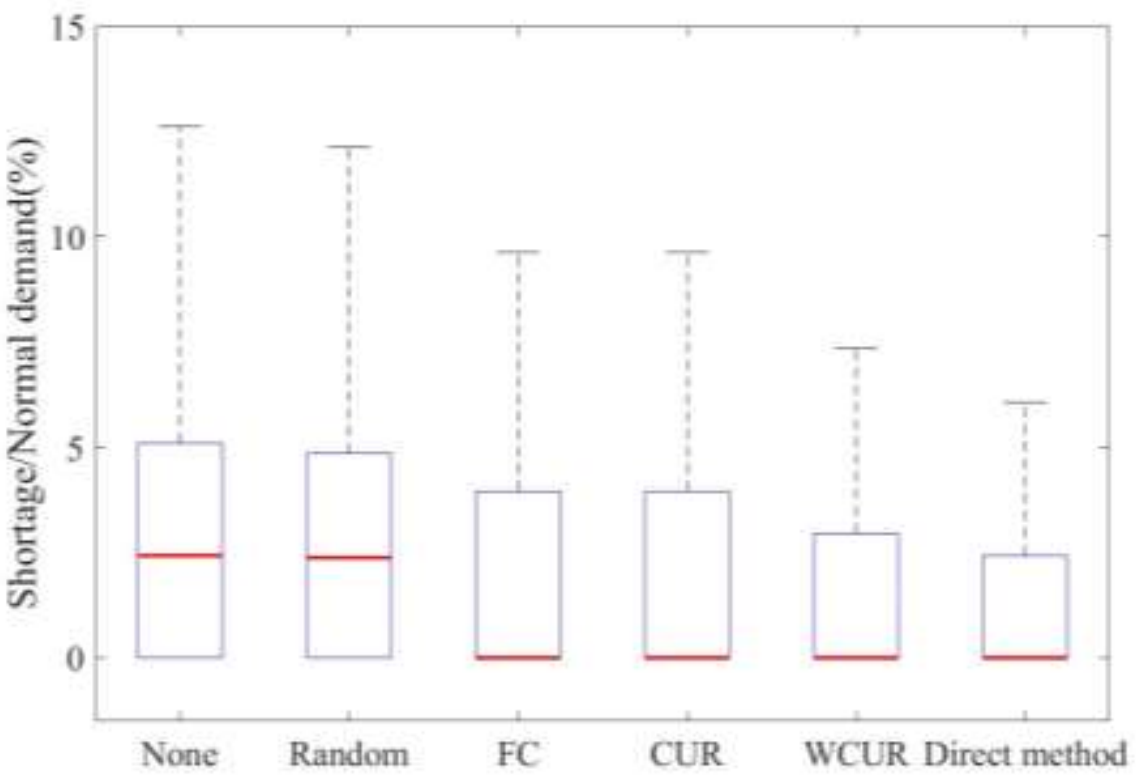

Fig.16. Global vulnerability by different preparedness policies (2 pipelines failures) 


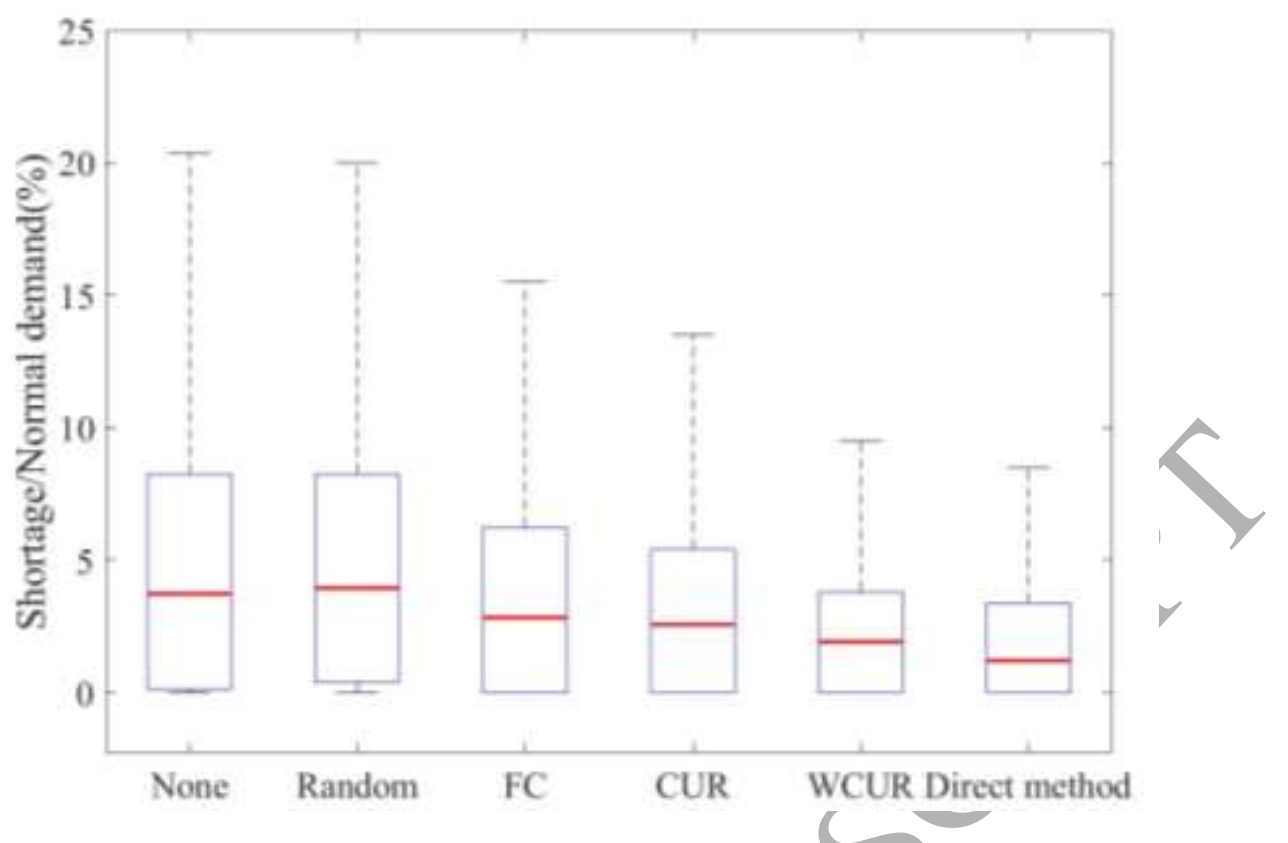

Fig.17. Global vulnerability by different preparedness policies ( 3 pipelines failures)

Table. 8 Supplementary information of vulnerability of the gas pipeline network by preparedness policy

\begin{tabular}{|c|c|c|c|c|c|c|}
\hline \multirow[b]{2}{*}{ Preparedness policy } & \multicolumn{4}{|c|}{1 pipeline failure 2 pipelines failures } & \multicolumn{2}{|c|}{3 pipelines failures } \\
\hline & & & $\begin{array}{c}\text { Mean } \\
(\%)\end{array}$ & Var & $\begin{array}{c}\text { Mean } \\
(\%)\end{array}$ & Var \\
\hline & & 10.6810 & 3.56 & 21.4418 & 5.43 & 31.1725 \\
\hline & 1.64 & 9.9396 & 3.32 & 19.7303 & 5.19 & 31.0670 \\
\hline & 1.18 & 7.5478 & 2.63 & 15.9442 & 4.13 & 24.2986 \\
\hline & 1.22 & 7.1694 & 2.49 & 15.5472 & 3.85 & 23.4916 \\
\hline & 1.01 & 4.4145 & 1.89 & 10.2381 & 2.70 & 12.8957 \\
\hline Direct attack & 0.93 & 4.6173 & 1.37 & 4.1023 & 2.19 & 8.3089 \\
\hline
\end{tabular}

According to the information in Figs. 15-17 and Table 8, it is concluded that all the criticality-based policies can significantly reduce the loss compared with "do nothing" and "random policy". The combination index, WFCR, is much more effective than $F C$ and $F C R$, and is just a little worse than the criticalities based on direct consequence calculation. However, the 
computation burden of the flow-based method is far less than the direct attack method.

\section{Conclusion}

In this work, we have developed a framework for the vulnerability analysis of supply service of natural gas pipeline networks. The developed framework has been applied to a natural gas pipeline network system and the results have been analyzed. Considering the characteristics of the "source-transmission-demand" system, the analysis includes three aspects: global vulnerability analysis, robustness analysis of demand sites and critical pipelines analysis. A systemic consequence analysis model has been developed based on a max-flow algorithm embedded in an optimization scheme, to evaluate the performance of the system or the consequences after the strains are imposed on it.

In the global vulnerability analysis, a comprehensive picture of the capacity of the system to withstand the strains has been presented. Three kinds of hazards or threats have been considered: degeneration of transmission capacities of the pipelines, drop of capacities of the gas sources and rise of demands from the customers. Under each of the strains, the system presents different properties which have been analyzed in the case study. In general, the system considered has a relatively strong ability to withstand the strains imposed.

Considering the important roles of the demand sites in society and economy, the abilities of the demand sites to tolerate the disturbance have been analyzed, and the reason of the different responses has also been explored. To quantify this, two indices, average level of unsatisfied demand (ALUD) and supply service robustness (SSR), have been proposed. The graph-theory perspective has been further considered. Two indices, average path length and topology efficiency, have been used to represent the connection between the abilities of the demand sites and their 
graph properties. The results in the case study show strong relationships between supply service robustness and the graph properties.

The criticalities of the pipelines in the system have been measured by the direct "attack-consequence" method. Considering the large computational cost of this method when it is used for large complex pipeline networks, a flow-based criticality measurement has been used in this work. The flow-based method combines the capacity and the topology contribution of a pipeline to represent its criticality to the supply service of the global system. In the case study, both approaches have been performed and their effectiveness has been compared to the "random attack \& preparedness policy" simulation. The results show that aceuracy of the flow-based method is slightly lower than that of the direct "attack-consequence" method; however, the computation burden of the latter is much higher than that of the former.

In the future work, a more detailed analysis will be performed by considering more detailed thermal-hydraulic properties and transmission operation technologies of natural gas pipeline networks. Other factors will be considered in the future work for improving the measure of the pipeline criticality. Besides, the market behaviors will also be included in the framework. The future research will focus on both the vulnerability and the recoverability of the system.

\section{Acknowledgement}

This work is supported by the fund [grant number 51134006]. 


\section{References}

[1] B. Shaffer, "Natural gas supply stability and foreign policy," Energy Policy, vol. 56, pp. 114$125,2013$.

[2] P. Zeniewski and R. Bolado-Lavin, "A review of national gas emergency plans in the European Union," Energy Policy, vol. 49, pp. 652-662, 2012.

[3] V. Vivoda, "Natural gas in Asia: Trade, markets and regional institutions," Energy Policy, vol. 74, no. C, pp. 80-90, 2014.

[4] E. Zio, The Monte Carlo Simulation Method for System Reliability and Risk Analysis. London: Springer London, 2013.

[5] A. H. Marvin Rausand, System Reliability Theory:Models, Statistical Methods, and Applications. Wiley-Interscience, 2003.

[6] E. Zio, "Challenges in the vulnerability and risk analysis of critical infrastructures," Reliab.

Eng. Syst. Saf., vol. 152, pp. 137-150, 2016.

[7] T. Aven, “A semi-quantitative approach to risk analysis, as an alternative to QRAs," Reliab.

Eng. Syst. Saf., vol. 93, no. 6, pp. 790-797, 2008.

[8] G. E. Apostolakis, "How useful is quantitative risk assessment?," Risk Anal., vol. 24, no. 3, pp. 515-520, Jun. 2004.

[9] N.Doorn and S. O. Hansson, "Should probabilistic design replace safety factors?," Philos.

Technol., vol. 24, no. 2, pp. 151-168, Jun. 2011.

[10] J. Johansson, H. Hassel, and E. Zio, "Reliability and vulnerability analyses of critical infrastructures: Comparing two approaches in the context of power systems," Reliab. Eng. Syst. Saf., vol. 120, pp. 27-38, 2013. 
[11] E. Zio, "Some Challenges and Opportunities in Reliability Engineering," IEEE Trans. Reliab., vol. PP, no. 99, pp. 1769-1782, 2016.

[12] J. Fang, C. Su, Z. Chen, haishun sun, and P. Lund, "Power System Structural Vulnerability Assessment based on an Improved Maximum Flow Approach,” IEEE Trans. Smart Grid, vol. 3053, no. c, pp. 1-1, 2016.

[13] G. J. Correa and J. M. Yusta, "Grid vulnerability analysis based on scale-free graphs versus power flow models,” Electr. Power Syst. Res., vol. 101, pp. 71-79, 2013

[14] Y. Ashibani and Q. H. Mahmoud, "Cyber physical systems security: Analysis, challenges and solutions," Comput. Secur., vol. 68, pp. 81-97, 2017.

[15] S. M. Wilkinson, S. Dunn, and S. Ma, "The vulnerability of the European air traffic network to spatial hazards," Nat. Hazards, vol. 60, no. 3, pp. 1027-1036, 2012.

[16] M. Ouyang, Z. Pan, L. Hong, and Y. He, "Vulnerability analysis of complementary transportation systems with applications to railway and airline systems in China," Reliab. Eng. Syst. Saf., vol. 142, pp. 248-257, 2015.

[17] W. Kröger and E. Zio, "Chap1 Introduction and Definition of Key Terms,” in Vulnerable systems, no. 1997, London: Springer London, 2011, pp. 1-7.

[18] N. Khakzad and G. Reniers, "Using graph theory to analyze the vulnerability of process plants in the context of cascading effects," Reliab. Eng. Syst. Saf., vol. 143, pp. 63-73, 2015.

[19] P. Praks, V. Kopustinskas, and M. Masera, "Probabilistic modelling of security of supply in gas networks and evaluation of new infrastructure," Reliab. Eng. Syst. Saf., vol. 144, pp. 254-264, 2015.

[20] E. Zio and L. R. Golea, "Analyzing the topological, electrical and reliability characteristics of a 
power transmission system for identifying its critical elements," Reliab. Eng. Syst. Saf., vol.

101, pp. 67-74, 2012.

[21] E. Zio and R. Piccinelli, "Randomized flow model and centrality measure for electrical power transmission network analysis," Reliab. Eng. Syst. Saf., vol. 95, no. 4, pp. 379-385, 2010.

[22] H. D. Mo, Y. F. Li, and E. Zio, "A system-of-systems framework for the reliability analysis of distributed generation systems accounting for the impact of degraded communication networks," Appl. Energy, vol. 183, pp. 805-822, 2016.

[23] F. Cadini, G. L. Agliardi, and E. Zio, "Estimation of rare event probabilities in power transmission networks subject to cascading failures," Reliab. Eng. Syst. Saf., vol. 158, pp. 9-20, 2017.

[24] C. Lo Prete and B. F. Hobbs, "A cooperative game theoretic analysis of incentives for microgrids in regulated electricity markets," Appl. Energy, vol. 169, pp. 524-541, 2016.

[25] M. X. Cheng, M. Crow, and Q. Ye, “A game theory approach to vulnerability analysis: Integrating power flows with topological analysis," Int. J. Electr. Power Energy Syst., vol. 82, pp. 29-36, 2016.

[26] K. Hausken, "Defense and attack of complex and dependent systems," Reliab. Eng. Syst. Saf., vol. 95, no. 1, pp. 29-42, 2010.

[27] E. Ferrario, N. Pedroni, and E. Zio, "Evaluation of the robustness of critical infrastructures by Hierarchical Graph representation, clustering and Monte Carlo simulation," Reliab. Eng. Syst. Saf., vol. 155, pp. 78-96, 2016.

[28] K. Hausken and J. Zhuang, "Game Theoretic Analysis of Congestion, Safety and Security," Springer, 2015. 
[29] K. Hausken and G. Levitin, "Minmax defense strategy for complex multi-state systems,"

Reliab. Eng. Syst. Saf., vol. 94, no. 2, pp. 577-587, 2009.

[30] K. A. Pambour, R. Bolado-Lavin, and G. P. J. Dijkema, “An integrated transient model for simulating the operation of natural gas transport systems," J. Nat. Gas Sci. Eng., vol. 28, pp. $672-690,2016$.

[31] E. Zio, "Vulnerability and Risk Analysis of Critical Infrastructures," Vulnerability, Uncertainty, Risk, vol. 1, no. 2, pp. 23-30, 2014.

[32] I. Prodan, E. Zio, and F. Stoican, "Fault tolerant predictive control design for reliable microgrid energy management under uncertainties," Energy, vol. 91, pp. 20-34, 2015.

[33] E. Kuznetsova, Y. F. Li, C. Ruiz, and E. Zio, “An integrated framework of agent-based modelling and robust optimization for microgrid energy management," Appl. Energy, vol. 129, pp. 70-88, 2014.

[34] J. Xing and E. Zio, “An integrated framework for business continuity management of critical infrastructures," Sep. 2016.

[35] F. Han, I. Prodan, and E. Zio, “A framework of model predictive control for the safety analysis of an electric power microgrid," in Safety and Reliability of Complex Engineered Systems, CRC Press, 2015, pp. 1553-1564.

[36] Z. Wang, G. Chen, D. J. Hill, and Z. Y. Dong, “A power flow based model for the analysis of vulnerability in power networks," Phys. A Stat. Mech. its Appl., vol. 460, pp. 105-115, 2016.

[37] M. S. Dehghani and H. D. Sherali, “A resource allocation approach for managing critical network-based infrastructure systems," IIE Trans., vol. 48, no. 9, pp. 826-837, 2016.

[38] A. Dwivedi and X. Yu, “A maximum-flow-based complex network approach for power system 
vulnerability analysis," IEEE Trans. Ind. Informatics, vol. 9, no. 1, pp. 81-88, Feb. 2013.

[39] C. D. Nicholson, K. Barker, and J. E. Ramirez-Marquez, "Flow-based vulnerability measures for network component importance: Experimentation with preparedness planning,” Reliab. Eng. Syst. Saf., vol. 145, pp. 62-73, 2016.

[40] L. Podofillini, E. Zio, D. Mercurio, and V. N. Dang, "Dynamic safety assessment: Scenario identification via a possibilistic clustering approach,” Reliab. Eng. Syst. Saf., vø1. 95, no. 5, pp. 534-549, 2010.

[41] A. T. Murray, T. C. Matisziw, and T. H. Grubesic, "Critical network infrastructure analysis: Interdiction and system flow," J. Geogr. Syst., vol. 9, no, 2, pp. 103-117, 2007.

[42] R. Faturechi and E. Miller-Hooks, "Travel time resilience of roadway networks under disaster," Transp. Res. Part B Methodol., vol. 70, pp. 47-64, 2014.

[43] A. Cherp and J. Jewell, "The concept of energy security: Beyond the four as," Energy Policy, vol. 75 , pp. $415-421,2014$.

[44] H. Demirel, M. Kompil, and F. Nemry, "A framework to analyze the vulnerability of European road networks due to Sea-Level Rise (SLR) and sea storm surges," Transp. Res. Part A Policy Pract., vol. 81, pp. 62-76, 2015.

[45] M. Ouyang, M. Xu, C. Zhang, and S. Huang, "Mitigating electric power system vulnerability to worst-case spatially localized attacks," Reliab. Eng. Syst. Saf., vol. 165, pp. 144-154, 2017.

[46] C. Dieckhöner, S. Lochner, and D. Lindenberger, "European natural gas infrastructure: The impact of market developments on gas flows and physical market integration," Appl. Energy, vol. 102, pp. 994-1003, 2013.

[47] P. Palensky and D. Dietrich, "Demand side management: Demand response, intelligent energy 
systems, and smart loads," IEEE Trans. Ind. Informatics, vol. 7, no. 3, pp. 381-388, Aug. 2011.

[48] F. Wang, H. Xu, T. Xu, K. Li, M. Shafie-khah, and J. P. S. Catalão, "The values of market-based demand response on improving power system reliability under extreme circumstances," Appl. Energy, vol. 193, pp. 220-231, 2017.

[49] Y. F. Du, L. Jiang, Y. Z. Li, J. Counsell, and J. S. Smith, "Multi-objective demand side scheduling considering the operational safety of appliances," Appl. Energy, vol. 179, pp. 864$874,2016$.

[50] P. Siano, "Demand response and smart grids - A survey," Renew. Sustain. Energy Rev., vol. 30, pp. 461-478, 2014.

[51] G. Levitin and K. Hausken, "Meeting a demand ys. enhancing protections in homogeneous parallel systems,” Reliab. Eng. Syst. Saf., vol. 94, pp. 1711-1717, 2009.

[52] "PipelineStudio | Energy Solutions." [Online]. Available: http://www.energy-solutions.com/products/esi-operational-management-solutions/pipelinestudi o/. [Accessed: 20-Jul-2017].

[53] R. K. Ahuja, T. L. Magnanti, and J. B. Orlin, Network Flows: Theory, Algorithms, and Applications, 1st ed. Prentice Hall, 1993.

[54] Y.Deng, Q. Li, and Y. Lu, “A research on subway physical vulnerability based on network theory and FMECA,” Saf. Sci., vol. 80, pp. 127-134, 2015.

[55] Z. Wang, G. Chen, D. J. Hill, and Z. Y. Dong, "A power flow based model for the analysis of vulnerability in power networks," Phys. A Stat. Mech. its Appl., vol. 460, pp. 105-115, 2016.

[56] C. D. Nicholson, K. Barker, and J. E. Ramirez-Marquez, "Flow-based vulnerability measures 
for network component importance: Experimentation with preparedness planning," Reliab. Eng.

Syst. Saf., vol. 145, pp. 62-73, 2016.

[57] Y. Fang and E. Zio, "Hierarchical Modeling by Recursive Unsupervised Spectral Clustering and Network Extended Importance Measures to Analyze the Reliability Characteristics of Complex Network Systems,” Am. J. Oper. Res., vol. 3, no. 1, pp. 101-112, 2013.

[58] L. C. Freeman, S. P. Borgatti, and D. R. White, "Centrality in valued graphs: A measure of betweenness based on network flow," Soc. Networks, vol. 13, no. 2, pp 141-154, Jun. 1991. 